. 


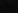



$=$
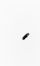


\section{Digitized by the Internet Archive in 2007 with funding from Microsoft Corporation}




\title{
THE ECONOMIC BASIS
}

\author{
OF
}

\section{PROTECTION.}

\author{
BY \\ SIMON Ne. PATTEN, Ph.D.,
}

PROFEgSor OF POLTTICAL ECONOMY, WHARTON gChOOL OF FINANCE AND ECONOMY, UNIVERSITX OF PENNSYLVANIA.

SECOND EDITION.

PHIIS DEL PHIA:

J. B. LIPPINCOTT COMPANY.

1895.

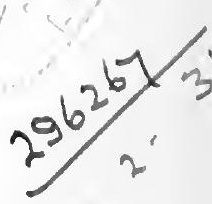


Copyright, 1890, by J. B. LippincotT Compaxy.

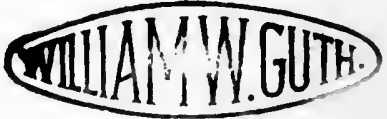

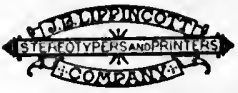




\section{CONTENTS.}

OHAPTER
PAGR

I.-Introduction ........... 5

II.-The Premises of the Present Discussion . . . 10

III.-The Growth of Economic Doctrine . . . . . 17

IV.-Fallacies disproved by Time. . . . . . 27

V.-Natural Monopolies fostered by Free-Trade . . 45

VI.-What fixes the Rate of Wages . . . . . 54

VII.-The Cost of Labor . . . . . . . . . . 64

VIII.-The Cost of a Passive Policy . . . . . . . 71

IX.-Where Foreign Commerce is a National Loss . . 81

X.-Obstacles to Economic Progress . . . . . 94

XI.-The Future of Raw Material . . . . . 106

XII.-The Consumption of Wealth . . . . . . 114

XIII.-The Criterion of Efficient Production . . . . 126

XIV. - Shall the Ideal of American Civilization be Na-

tional or Cosmopolitan ? . . . . . 136 



\section{THE ECONOMIC}

\section{BASIS OF PROTECTION.}

\section{CHAPTER I.}

\section{INTRODUCTION.}

The discussion of international trade has always excited much interest, and must, for a long time, still command the attention of all thoughtful citizens. A great variety of arguments has been presented to the public and many of them are already fully discussed. Yet there seems to be a place and an opportunity at the present time for a new discussion of this important problem upon a more fundamental basis than is usually found in former treatises.

We do not now need new facts so much as a discussion of the relation of these facts to one another, and the bearing of all this class of facts upon economio doctrine. Above all, we need a discussion on a purely economic basis. In the past very few of the writers upon this subject have carefully separated the economic arguments against protection from the moral and political, and in this way the former is subordinated to the latter. Many writers start also from the assumption 
that the most fundamental right of property is that of free exchange. They thus introduce premises which are appropriate to other fields of thought. Deductions from political dogmas are often substituted for a real economic discussion, and in this way clear thinking is subordinated to inherited feelings. Others assume a moral tone, and assert as a fundamental doctrine that protection in any form is a robbery, - that it takes from one individual what it gives to another and thus violates the rights of all. Such arguments, however great a force they may have upon persons of a particular political and moral education, are really not economic in their nature, and should be separated from strictly economic discussions so that the real bearing of industrial facts may become manifest.

- My purpose is also to show the growth of economio thought in its relation to the doctrine of protection. There has been a gradual change in the fundamental principles of political economy since Adam Smith first brought the doctrine of free-trade into prominence. Many of the doctrines of Adam Smith, upon which his theory of free-trade rests, have been displaced by other doctrines more in harmony with the present conception of the doctrine of protection. Free-trade by sinking into a creed has lost its scientific basis.

The older doctrines of protection were short-sighted, in that they sought for protection merely for specific ends. Some writers having in mind the growth of population advocate protection that the nation of which they form a part may grow more rapidly in population, thinking that with the growth of population will come 
that growth in material resources upon which national prosperity depends. Others again have emphasized national independence, and have sought to show how necessary it was for national welfare to be independent of foreign nations in all important departments of production. This point of view was especially important at an earlier time, when the danger of war with foreign nations was more prominent than at the present time. Another class of writers have emphasized what may be termed the "infant industry argnment," and say that new industries need the aid of the government to develop them in order that they can stand the competition from foreign countries. This argument assumes that the nation to which protection is applied is less advanced in civilization than other nations with which it has commercial relations, and that it is desirable on the part of the new country to assimilate the conditions with foreign countries.

These various arguments have had great force at particular periods of a nation's development, yet they are not sufficient in themselves to form the groundwork of economic doctrine. We now need a systematic presentation of all these points of view, so that the thought which lies at the basis of all of them may be clearly seen. The new point of view should include all these cases, and also be able to show the principles upon which they rest. Protection now changes from a temporary expedient to gain specific ends to a con sistent endeavor to keep society dynamic and pro gressive. Protection also ceases to be an isolated exception to the general passive policy which it has been 
popular to advocate, and becomes a part of a fixed national policy to increase the value of labor with the increase of productive power, and to aid in the spread of knowledge and skill and in the adjustment of a people to its environments.

I do not advocate protection in the case of our own nation, for example, because we are a backward country needing a special means to bring us up to the level of more progressive nations. In this respect I differ from the older economists who advocated a protective policy. They seem to imply that it is good for the American people to approximate European conditions. On the other hand, I would differentiate as much as possible our industrial conditions from those of Europe. We should not accept the ideal of European civilization as that best fitted to American conditions. We need most of all a new ideal which will conform to the industrial phenomena which have become prominent in America. It is especially important that we should keep in mind that an ideal growing out of present American conditions must harmonize with the dynamic state of American society. In this respect our ideal must stand in sharp contrast with the static ideal advocated by most free-traders. The older theories of economics have always pushed to the front the conception of a static society in which all the various elements would harmonize, and thus form the highest state of civilization. The ideal that I wish to emphasize, on the contrary, is based on the changing dynamic conditions which are necessary for any people to pass through in its progress towards the highest possible social state. 
A dynamic theory of social progress is quite distinct from a static theory of a passive industrial state. I shall sharply oppose the ideal of the one theory to that of the other, and in this way make prominent those conditions which force nations to become more progressive, and to overcome the obstacles which tend to bring them prematurely into a static state.

Contrary as it may seem to popular opinion, the theory of a subject must always be developed previous to any intelligent study of the facts. The truth of this point of view has been verified by past experience, and will find additional proof in the future. Just as the cosmopolitan theory, advocated by Adam Smith, upon which free-trade is based, was a theory for a long time before it was carried into practice by the English people; so at the present time believers in protection need first of all a consistent theory of the causes of national progress, so that all the facts with which we are familiar may be brought in harmony with this theory and thus form its verification in experience. A leading purpose, therefore, in this essay, will be to present an ideal of a society in a dynamic condition as counterpart to the ideal of a static state. I shall feel satisfied if I succeed in showing that such an ideal corresponds to the leading features of American industrial conditions and is in complete harmony with the best development of our industrial resources. Whether we shall have a static or dynamic society is really the centre of the discussion about the tariff. All other issues are secondary to this, and can be decided only when the main issue is out of the way. 


\section{CHAPTER II.}

\section{THE PREMISES OF the PRESENT DISCUSSION.}

IT will be seen, from what has already been said, that I am not a believer in the theory that there is but one system of political economy, the doctrines of which hold true for every civilization. Each nation in its own industrial conditions has perhaps all the economic causes at work which influence any other civilization, yet the relative importance of each of these causes varies with the industrial condition of each people. Not only is this true, but the prominent causes operating in any nation at one time are not likely to be the same as the prominent causes which have operated in that nation at a much earlier period or will operate in the same nation in the distant future. For this reason, if we wish to have the economic policy of any nation correspond to the actual social conditions which are prominent in that nation, it is not necessary to start with an examination of all those theoretical causes which might influence the economy of any nation. It will lead to much better results if we confine ourselves primarily to those causes which are prominent in the nation the industrial conditions of which it is our purpose to investigate.

The basis of an American political economy should result from an examination of the present economic 
environment of the American people. We have prominent in our present social conditions many economic causes, which although they may not be new, yet they never have been the leading characteristic in the economy of any people before the present time. The theory which I shall advance will make certain assumptions as to the prominent facts in American economy, and these assumptions I wish to bring forward in an orderly manner, so that the limitations of the discussion upon which I am about to enter may be clearly seen.

First, I shall assume that the American people are in a dynamic state. There is at the present time a constant growth of population, and hence an increased number of laborers must find employment in some way. We must therefore continually seek for new opportunities for labor in which this increase of population can find employment. I shall, in addition, assume that the American people are in a more dynamic state than that of other competing nations. Many of the obstacles which keep the people of Europe static have little or no force in America at the present time. We are not bound down by the necessities of the military rule, nor have habit and custom that force in keeping the people in their old lines of occupation that is true of European countries. As a result, the American people should be more progressive than those of Europe. The soil we occupy is newer than that of Europe, the mines of which we make use are superior to those of foreign countries, and these conditions, coupled with the spirit of activity which fills the American people, should push us along into a higher state of civilization much 
more rapidly than it is possible for the people of older civilizations to advance.

Second, I shall assume that the American people are not at the present time adjusted to their economic environment. A large part of the inhabitants of America have come from foreign countries, and even those whose fathers or perhaps grandfathers were born upon American soil have not yet lost those habits and customs, those modes of thought, and those articles of diet to which their ancestors were accustomed while in Europe. Our agriculture must be dissimilar to that of Europe, because our climate and soil are different. The crops that flourish in Germany, France, and England are not those best adapted to American soil. Even the clothing which European nations use are not of that character which is best suited to American climate. The winters are not as cold as ours nor are their summers as warm. As a result, they can be comfortably clothed in a way which would be entirely unsuited to American conditions. In fact, Americans must adjust themselves to a tropical climate in the summer and an arctic climate in the winter, and in the end this necessity will force them to modify their clothing in a way that will make it quite distinct from that of Europeans. Many other radically dissimilar economic conditions to which American people must adjust themselves might also be pointed out which will make the typical American of the future different from the typical European.

Third, I shall also assume that at the present time there is a strong tendency in America to increase the 
share in the distribution of wealth which goes to rent and other natural monopolies. Economic theory has not yet given due consideration to the strong tendencies which are now present in American conditions to increase the share of those who are protected from competition at the expense of those who must compete with one another upon equal footing. If American conditions are such as to bring forward this tendency to a much greater degree than has been shown in any previous civilization, there must be, on the part of the American people, a corresponding change in American economic policy so as to adjust themselves to these new conditions.

This premise is of especial importance in a discussion of the tariff, because it breaks down the chain of reasoning by which the free-trade position is upheld. Where producers and consumers deal directly with one another cheap production results in cheap commodities. Increase the waste of distributing commodities, or let strong monopolies grow up between producers and consumers, and cheap production may go hand in hand with high prices to consumers.* Under these conditions increased cheapness on the part of producers does not give a proportional benefit to consumers. It may be wasted in useless competition or pass into the hands of the monopolies which free commerce has created, by separating the producer so widely from the consumer.

My conclusions, therefore, are not meant to be gen-

* See my "Rational Principles of Taxation," page 4. 
eral; nor shall I emphasize those general economic theories which are true of all civilizations. I shall restrict myself at the present time to a society in which these premises to which I have referred are true. Any marked change in these premises would bring into prominence a new series of economic problems and make invalid the conclusions which I draw from them.

If I have correctly analyzed the salient features of present American civilization, then the conclusions which I shall draw are valid of American conditions. It is, therefore, quite possible that the best economic policy for America may be very different from that of other nations. In fact, this is what I should expect. I do not desire to have the conclusions which I shall present judged by foreign conditions, because our economic conditions are so different from those of any foreign nation that an American industrial policy must be of a distinct type from that of other nations. To show, therefore, that free-trade has been successful in England does not prove that it would be beneficial to us. The success of this experiment in England was due to particular causes which cannot have much foroe in America at the present time. Previous to that time there had been no free-trade nation, and all civilized countries needed a world's market. We all gain by having the various national economies brought into contact along many lines. This was impossible so long as every nation followed a restrictive policy. England was the first nation to open up a world's market, and, as a result, not only all England became more prosperous, but all other nations acquired an advantage from 
the free markets of England. The world now has such a market. A second market of the same kind would not have that effect on the development of industry that followed the opening up of the English markets. One nation may make a great gain by putting itself in contact with other civilizations and becoming a market for their surplus; but a second nation would find the field occupied. At most, we can hope to divide this trade with England, or possibly to undersell England in such a manner as to absorb this whole trade to ourselves. The mere displacement of England by America, while it might be of some advantage to particular classes in America, would not be a gain for the whole world. The world's progress is now dependent upon the development of internal resources, and not of external trade. We need a systematic development of all those opportunities for labor with which each country has been endowed by nature. We must make a better use of all our natural resources if the world is to advance to a higher industrial state. Progress must come from the development of large continental nations, rich in natural resources. Small nations, deficient in many of those natural resources needed for a nation's development, must rely largely upon trade to obtain those things in which their resources are deficient. To such a nation the profits of trade can to a large degree be accepted as the criterion of national prosperity; but large continental nations must look nearer the real source of national prosperity to obtain their criterions. They must become successful by the development of their natural resources. Their land 
and their mines must be opened up and the productive capacity of each laborer must be increased. Only after all the possibilities of land have been carefully investigated and the industrial qualities of the people carefully examined, can they discover what national policy will bring to them the greatest industrial prosperity. 


\section{CHAPTER III.}

THE GROWTH OF ECONOMIC DOCTRINE.

So little attention has been paid to the history and gradual development of economic theory that the public have very misty ideas as to the relation of freetrade to economic doctrine. The development of the doctrine of free-trade is largely due to Adam Smith, or at least we may say that he was the first one to present it in a systematic way to the thinking world. Since the groundwork of the creed of free-trade is to be found in his writings and those of his disciples, I desire to examine into the premises from which they start, so as to show in what ways these doctrines have been undermined by later economic progress.

The criterion of prosperity which Adam Smith uses is that of profit of the individual. If an exchange is profitable to the parties directly interested, he assumes that it is beneficial to the nation. In this way the individual profit of producers becomes a criterion of national prosperity. Under the new conditions of production which have arisen since the time of Adam Smith, a sale profitable to the producer does not indicate that it has been also advantageous to the public in the way that a like sale for a corporation would indicate the advantage of all the stockholders. We have no means by which the advantage derived in an ex- 
change can be divided among the various groups of producers in the way a stock company divides the proceeds of its sales. In fact, it can often happen that the advantage of one party in an industrial operation may result in a disadvantage to the other interested parties. Adam Snith, in his investigations of the productive power of nations, also confines himself too exclusively to the division of labor, and continually emphasizes the importance of this feature of modern production. He regards the division of labor as the cause of national prosperity. Subsequent investigations show the disadvantages of the division of labor, and that the increase of productive power is often antagonistic to the use of men and of land for one thing only in the way which Adam Smith advocates.

Passing from the position of Adam Smith to that of Ricardo, we have a great advance in economic dootrine. Ricardo also was an advocate of free-trade, and some of his arguments are particularly emphasized in free-trade discussions. It is, however, unfortunate for the validity of these arguments that they are based on that part of the doctrine of Ricardo which has since been discarded by modern economists. The economic man of Ricardo harmonizes nicely with the free-trade conception of men. If man were as simple in his mechanism as Ricardo supposes, and had but one industrial quality developed, the social conditions which would result would harmonize fully with free-trade doctrines. In the same way Ricardo's conception of land brought out that use of land which free-traders emphasized. If all the land of the world were merely 
wheat land, then we should have an economic basis upon which free-trade might rest. We now know that the economic man of Ricardo was merely an ideal and not the actual man which we find in society, or even in any possible society with a high civilization. Men have numerous industrial qualities, all of which must be developed if they are to make the most of their economic environment. We know also that Ricardo's conception of land was as faulty, or perhaps I should say as ideal, as that of his economic man. There is no land from which society can acquire any considerable advantage as long as it is used for any one purpose. The cultivation of wheat or any other single crop soon deteriorates the qualities of the soil. Land does not have any indestructible qualities which will allow its use in any one way without serious economic disadvantage. For these reasons that conception of men and land, of which Ricardo makes so much use, cannot be accepted as the basis of a progressive national economy. So far as free-trade has such a conception as its basis, it is not a policy which will lead to the greatest increase of the productive power of any nation; and the reliance which free-traders still have on this point of view has put them out of harmony with the later growth of economic doctrine.

While free-traders have accepted and relied upon that part of the doctrines of Ricardo, which have been proved false by later investigations, they have neglected to. show the relation of the doctrine of freetrade to those parts of the economy of Ricardo which have been proved to be true. The leading doctrine of 
Ricardo is that of rent, and the study of rent has brought into prominence natural monopolies that interfere with the natural distribution of wealth. It has never been shown that the doctrine of free-trade leads to good results so long as a large share of the wealth produced is acquired by the owners of natural monopolies. The doctrine assumes that prices of all commodities stand in direct relation to the quantity of labor needed to produce these articles. If there were no natural monopolies this might be true, but as soon as the owners of natural resources secure as rent a large part of the productive power of the nation, the products of natural monopolies no longer exchange with other commodities in proportion to the quantity of labor veeded to produce them. When rent becomes an important factor in the distribution of wealth, the simple hypothesis upon which free-trade rests is no longer true. This part of the theory of Ricardo is now antagonistic to the free-trade doctrines based upon the other part of his theory which has since proved false.

From Ricardo's time economic theory and the creed of free-trade have no longer harmonized. The doctrine is now championed by a new class of thinkers who cannot be regarded as strictly economic. The introduction of free-trade in England caused these writers to empliasize the results of free-trade as the best evidence of the correctness of that policy and to neglect the theoretical proofs advanced by earlier economists. This change is accompanied by the rise of the Manchester party in England. Exchange is now put forward as the fundamental fact of all economic science. 
No further analysis of economic phenomena is made other than would show the profit of exchange in general. Many writers now limit economic science to an exposition of exchange, and in this movement Bastiat took the lead, and soon he became the prominent leader of the free-trade movement. He entirely - neglects the influence of rent and the effect of the rapidly-increasing value of all natural monopolies. In fact, he tries to disprove that there is any such thing as rent. In this way the popular free-trade movement came in direct opposition to better economic thought, and the lines of distinction between economic scholars and the adherents of the popular free-trade creed are very marked.

The later developments of economic theory have gradually increased the breach between free-trade doctrines and sound economics. The cost of production had been viewed by Ricardo and also by Mill from the stand-point of the employer only. Cost of production was made to consist of the wages of laborers and the profits of employers. So long as the leading arguments of protective writers were limited to a point of view that emphasized national prosperity and failed to analyze the distribution of wealth, this doctrine of the cost of production seemed a strong support to freetrade. About 1840 the laborers became separated into so distinct a class that their interests were no longer in complete harmony with those of their employers. The distribution of wealth now became the prominent problem of economic science, and the rights of laborers were sharply contrasted with those of their 
employers. Protection now assumes a new form and is advocated as a means of securing to the laborers a larger share in the distribution of wealth. The doctrine that the cost of production consists of the wages of laborers and the profits of employers gave a good basis of the economic argument now advanced by protectionists, and there was no other way that believers, in the doctrine of free-trade could meet the new arguments but by abandoning this conception of the cost of production. As a result, the doctrine of free-trade was left by Mill in as bad a shape as he left the doctrine of the wage fund or of value. If the old doctrines of free-trade, of value and of wages, were to continue to receive the support of economists, a new basis must be found upon which they could rest.

It was Cairnes who endeavored to close the breach which time had made in the old economy. He took up these three doctrines and by a careful re-examination sought to strengthen them by new arguments. It is now conceded that he failed in re-establishing the wage fund or in giving a better basis to the old doctrine of value. The tendency of recent thought has been in a contrary direction to the doctrines advanced by Cairnes. In considering value it is now acknowledged that Jevons and not Cairnes was on the right track; nor have the views of Cairnes upon the wage fund been accepted by as many economists as to have them considered good economic doctrine. The support he gave frec-trade is as defective as that of the other doctrines he endeavored to substantiate. He discarded the doctrine that the cost of proluction should be regarded as made up of 
wages and profits, and sought to bring into use a new conception of cost based upon a subjective rather than an objective point of view. Instead of the profits of employers and the wages of workmen we have now the sacrifice of the workmen themselves put as a basis of the cost of production. Under ideal conditions, where there are no natural monopolies, it is quite possible that commodities may have a value in proportion to the sacrifice of those who produce them. At the present time, however, the share of the whole product of industry which the owners of natural monopolies secure is too great to allow any such theory to correspond to all the facts about us. The cost of labor has an influence upon all exchanges now made, and the argument for protection which is based upon this point of view cannot be disproved while present economic conditions continue.

The theories, however, which harmonize with the doctrine of free-trade have been undermined in another direction still more fundamental than those which I have mentioned. The doctrine of free-trade is a part of the old economic system which assumes that there is a body of economic doctrines good for every people in every age. The old system was absolute because it did not allow any modifications due to changes in industrial conditions. It, was conceived as perpetual because it was thought to conform to the conditions of every nation in all stages of its progress; and it was cosmopolitan because it wished to create a single market into which the whole world would become united before its resources were fully developed. 
The rise of the historical economists displaced this conception of political economy. We no longer seek after a universal economy which will be good under all industrial conditions, but for one that is fitted to the people of a particular nation in a particular stage of its development. In every modification of the economical conditions of such a nation we now anticipate that new phenomena will come to the front in a way that will modify the economy of the nation. That a policy was good for one nation at a particular time is no longer regarded as sufficient evidence that it will be good for other nations, or for other times. The causes of national prosperity must be studied under the peculiar conditions of each nation, and the separate problems which its economy brings forward must be solved by a study of its own economic conditions.

In this way an economy such as I have outlined in the previous chapter is in harmony with the mode of thinking now prevalent among economists. American conditions must be investigated before we can ascertain what policy will be best suited to the American people, and if we find that several leading characteristics in that economy are different from what we find in other nations, we have the conditions which force us to separate the theory of American economy from that of other nations.

In still another way has the doctrine of free-trade become antagonistic to economic thought. At the time of Adam Smith political ideas were the dominant ones. The prevailing system of thinking was based upon the doctrine of natural liberty. There were no sharply- 
drawn lines which separated political economy from political science, and as a result economic and political premises were so intermingled that many doctrines regarded as economic had no economic basis. However true it may be that a passive policy has the support of our inherited ideas as to political rights, it cannot be accepted as economic doctrine until it has been based upon industrial facts. Such a verification of the economic benefits of non-intervention has not been developed. We now quite clearly see that modern industrial conditions force men to modify their ideas of natural liberty before they can make the best use of their material resources.

In all these ways economic science has been separated farther and farther from a point of view in harmony with the creed of free-trade, and in the future, political economy will separate itself still farther from the stationary position of free-traders, because it must investigate that class of economic phenomena separated most widely from that which free-traders emphasize. The theory of exchange has now become a very subordinate part of economic doctrine. More fundamental problems now occupy the attention of economists than that of market value and the profit of producers. In the future economic investigation must be based upon the primary facts which cause commodities to have a value to their possessors. The doctrine of utility has been so fully developed that the new axioms concerning value must displace the old ones that are based upon profit. In this way the theory upon which free-traders rely will be so far removed from economic science that 
we must think of the past age as having a distinct school of economists. Soon economic theory will be as far separated from the creed of free-trade expressed in the doctrines of the Manchester school as those doctrines are from that of the Mercantile school which they displaced.

Economics in the future must deal mainly with the dynamic conditions in which society now finds itself placed. Free-trade being a part of the economy of a static state does not apply to present conditions. The system of natural liberty which formed a basis of economic doctrine during the last century conceived society as moving towards an ideal static state, and the strength of the free-trade position rests in the sharplydefined ideal which is presented of such a static state. The dynamic condition of society at the present time requires a very different ideal from that which harmonizes with a static state. If we wish the doctrines of a dynamic state to have that force that the doctrines of a static state now have, a clear conception must be formed of the causes operating in a dynamic state and of the economy suited to a dynamic society. 


\section{CHAPTER IV.}

\section{FALLACIES DISPROVED BY TIME.}

IT is a prevalent practice of free-traders to go over all the discarded economic dogmas of the past, particularly those of the Mercantile school of economists, and then to represent them as the principles of modern protectionists. In this way protection is brought into discredit and a feeling created that the doctrine of freetrade corresponds more closely with the present state of economic knowledge. It is my purpose at the present time to examine the arguments used by free-traders and in this way show how many of their positions have been disproved by the outcome of subsequent events. Many of their leading arguments which seemed plausible and harmonized with the economic theories of the day, when examined at a later period by the light of actual results, show quite clearly the erroneous notions which were held in the past, and enable us to see that free-trade doctrines are not really based upon the best economic knowledge of to-day. The creed of free-trade is as much out of harmony with present industrial facts as the doctrines of the Mercantile school were with those facts at the time of Adam Smith.

The most frequent charge against protection is that it discourages international trade. Tariff is often represented as a Chinese wall, which shuts out each nation 
from any trade with its neighbors. Protectionists are represented as wishing for a tariff operated in a way that would cut off each nation from the benefits of commerce. This position, however, does not represent the truth about the protection doctrine. Protectionists do not desire to destroy foreign trade. They wish to develop foreign trade as much as their opponents do. The difference between the two policies lies in the kind of trade the nation should encourage and in the connection between foreign trade and national prosperity. Foreign trade is the effect, not the cause, of national prosperity, and protection increases foreign trade by increasing national prosperity. The higher price of one class of foreign articles will have the effect of creating a demand for another class by building up national industries and promoting national prosperity. A people with but few wants will necessarily satisfy most of them by the demand for home commodities. Every increase in the variety of consumption creates a demand for many articles which would not be desired by people so long as their condition was less prosperous and production confined to fewer articles. As the people become more prosperous their wants become more varied; and, through the greater variety in their wants, they will seek not only in their own country but also in foreign countries for those commodities which will satisfy their new wants. And, if other nations adhere to a sound national policy, their increased prosperity will lead them also to broaden their consumption, and thus create a demand for the commodities of the first nation. Wlatever broadens consumption, there- 
fore, has as a result an increase of foreign trade, through which both parties to the exchange add to their prosperity. This increase in foreign trade will not be in those articles on which the tariff has been laid, but in other articles. The effect of the increased prosperity coming from the tariff will cause each nation to demand so great a variety of articles that many of them cannot be found at home. If, then, there is a direct connection between the amount of foreign trade and national prosperity, protection will increase foreign trade, if protection is that policy which is best fitted to develop national prosperity.

A second fallacy of free-traders consists in assuming that the best use of land and of men is attained by using them for a single purpose. The illustrations upon which they rely to prove their position are taken from commerce and manufactures. It is shown how rapidly the productive power of men and of machines increases in our leading industries with the division of labor, through which each man and machine is used for some single purpose. They then assume that land is also put to its best use when employed in raising some one crop. They suppose that there is some land best fitted for wheat and upon which a continuous series of wheat crops can be obtained. Then other land is thought of as cotton land, and still other land as coffee land or sugar land. In this way, the whole land of the world is divided up into sections supposed to be devoted to some one purpose, just as the machines upon the market are known to be best used for some one end. This conception, however, is radically erro- 
neous. There is no piece of land which can give as great a return for oue crop as for a group of crops. Devote a piece of land to the continuous production of wheat and you take from the land a large share of its fertility. There will, after the first few years, be a steady diminution of the product, until at last the land will be exhausted and perhaps abandoned. In the same way the continuous production of tobacco upon land completely exhausts it, until finally it must be left to nature and becomes entirely worthless. We have in many parts of the South instances of this ruinous use of the soil for tobacco. The South affords another good illustration of this wasteful policy in the use of land for cotton, the same general law being at work through which a continuous use of land for one purpose ends in destroying its fertility.

If we are to make the best use of land we must look upon it not as we do upon a machine, but in the light of an agent whose best use requires a great variety of crops. I do not mean by this that each kind of soil is fitted for any crop, and that every crop must form a part in the rotation which its best use demands. There is, however, a group of products which is best fitted for each given piece of land. In Minnesota we need one series to produce the best results, in Louisiana another, in Florida still others. Now if this law be true, and land is better fitted for many uses than for one, it is erroneous to reason about it as if it were a machine. If on any given piece of land it requires, say, five crops for its best use, the price of produce may be such as will pay the producer to bring only one of tnem to 
market, or at least that one of the five is much more profitable than all the others. In this way, if freetrade is allowed, the land will be used for one purpose until exhausted, or there will be at least a strong tendency on the part of producers to obtain this one crop more often than is good for the soil.

The policy of a government desiring to develop its land most fully must necessarily be one that will create - in the vicinity of each class of lands a demand for all that group of products which is necessary for its best use. Until this is brought about there is no hope that the agriculture of the nation will be as progressive as it should be. The law of agricultural industry is, therefore, the opposite of manufacturing industry. The best use of land demands a variety of products, while a factory is more productive making one. Freetraders in regarding land as a machine, therefore, make a great mistake, and by following their reasoning a nation falls into serious errors.

Since, however, a variety of uses of the land does not mean to produce upon each piece of land every article, there are still the conditions necessary to create a large and prosperous trade between different parts of the world as soon as the variety in their diet becomes so great as to exceed those articles which are necessary for the best use of their own land. When the simple tastes of primitive people are enlarged there will be a continual increase in trade between different nations, even in agricultural commodities, and this trade. will grow with the prosperity of each part until at length it will be much greater than it could possibly 
be if an erroneous conception of the productive power of land should cause men to use it for one thing instead of, as it should be, for a great variety of purposes.

Another of the old standard arguments for freetrade now demands attention. The argument as usually presented by free-traders assumes that America has a special fitness for the production of wheat. All over the West, it is said, wheat is the crop best suited for the soil. On the contrary, England has its special advantage in the production of iron. Coal and iron have been placed by nature in close proximity in England, and as a result the cost of iron is much lower than elsewhere. As America has special advantages in the production of wheat and England in the production of iron, it will be profitable for both nations if America produces the wheat and England devotes itself to the production of iron. Is it true, however, that America is particularly fitted for the production of wheat, and that the ability of England to produce iron is greater than that of America? If this claim be examined from our present knowledge of the productive capacity of England and America, the answer must be, not that America is best fitted for wheat and England for the production of iron, but that England is especially adapted to the production of wheat while America has the better facilities for the production of iron. At first this may seem a remarkable statement, and the question naturally arises, if America is less fitted for the production of wheat and England for the production of iron, why has not the trade of this country gone in a contrary direction, so that America would 
produce the iron and England the wheat? Such a result would follow if the free-trade theory were correct, and hence we have a good test of the theory. Let us, then, cast aside the theory for a moment and examine the real facts of American and English production; because these facts will show that each of these countries under free-trade has a strong tendency to produce that for which it is least fitted. England has a marked advantage over America in the production of wheat, due to the peculiar conditions of English climate. Wheat is a cereal with short roots, not sinking deeply into the ground. Such crops thrive best where the soil is very damp and moist, and where a large quantity of rain falls at regular intervals during the period when the wheat is growing. American conditions are the reverse of those of England. We have dry, hot summers, often with long intervals between the rains, and as a result the surface of the ground becomes so hard that a crop like wheat, which does not root deeply, is at a serious disadvantage. This advantage of England for wheat is further proved by the statistics showing the production of wheat per acre in England and America. American soils usually do not yield more than twelve bushels an acre, and many years this amount is not obtained because of the severity of our climate and the abundance of insect life ; yet under English conditions twenty-six bushels an acre is not regarded a large crop, showing that under similar conditions an English acre will produce at least half as much again as the quantity obtained from the average American acre upon which wheat has been grown for foreign markets. 
On the other hand, if we examine into the conditions for the production of iron, it will be found that our beds of iron are purer than those of England and that our coal-beds are thicker than those from which English coal is obtained. As a result of this superior productivity of our iron and coal mines, the same quantity of labor in America can give a greater product than in England. This fact is now generally acknowledged even by free-traders, although until a very late date it has been denied. Our knowledge of American conditions compared with those of England is now so accurate that it is impossible for any one to deny the superior productivity of our iron and coal mines. Yet in spite of these facts trade between the United States and England actually has a tendency to increase in America the demand for wheat, although wheat is less fitted for American than for English soil, while the same commercial conditions increase in England the demand for iron, although American mines are superior to those of England. In this way it is seen that trade actually runs in an opposite direction to what the theory of free-trade supposes, and thus the falseness of the doctrine is clearly seen.

Another argument often advanced by free-traders is that protection impairs the moral independence of the people and causes them to be less enterprising and independent than otherwise, and that it creates in them a tendency to rely upon governmental aid instead of upon self-help. It was often asserted in the past that as a result of this reliance upon government for aid in maintaining high prices the American manufacturers 
made use of poor machinery, and did not exert that care they should to economize labor in their factories. For a long time these arguments were among the most popular used by free-traders, and there seemed to be many things which made them appear true, yet our present knowledge of productive processes in America shows clearly the falsity of this charge. There is no nation which makes a better use of machinery than the Americans, nor is there any place where the tendency for the improvement of productive processes is stronger, thus showing that a tariff need not in any degree impair the moral independence of a people. On the contrary, it seems in many respects to strengthen the enterprise of those who are protected by a tariff, since the higher cost of labor acts as an incentive to make a greater economy in its employment.

Time again has disproved the fallacy that the best opportunities for labor were first utilized. The old argument concerning the increase of production and in particular that of the increase in the quantity of land used in production asserts that the first settlers of a country pick out those locations from which they can obtain the greatest return. Each succeeding age finds that with the increase of population poorer lands must be brought into cultivation, and thus with the increase of population there is a gradual lowering of the margin of cultivation. Such was the position held by older economists, and such is the doctrine that lies at the basis of free-trade. If it were true, then there would be some good reasons for advocating a free-trade policy, but if it is shown that from the peculiar position 


\section{THE ECONOMIC BASIS OF PROTECTION.}

in which first settlers find themselves they are compelled to make use of the poorer classes of lands instead of the better, then we cannot affirm that freetrade tends to bring into use those classes of land which will give the highest return. The first settlers instead of coming upon the best lands are actually forced to cultivate many of the poorer soils, which are easily brought into cultivation or which are peculiarly adapted to the cultivation of those crops for which there is a foreign demand. For this reason some change in the demand for food must precede the best use of the land of a country. Some new market must be opened up which will afford a place where the new crops can be sold, thus enabling the producers to use their land in a better manner. With each extension of the home market new uses for the land are found, and at the same time many classes of soil which were worthless while the few crops demanded by foreigners were produced, now become the more productive part of the land. This fact is clearly illustrated in the changes of value in Western lands which have followed the creation of home markets. The lighter soils were first occupied because better adapted to the cultivation of wheat. These soils commanded a higher price than the heavier lands so long as the main market for the West was in Europe. But when the growth of home markets created a demand for corn instead of wheat, these heavier lands were brought into use, and soon came to be regarded as the better land; and at the present time they command a much higher price than do the lighter lands which were first used for wheat. 
A dynamic society passes from poorer to better land by increasing the variety of its food and the diversity of its occupations. It is only to a static society that the theory of free-trade is applicable. Here poorer resources are gradually brought into use through the exploration of natural advantages.

Another free-trade argument tries to show that protection results merely in higher values and does not give any one an advantage if all producers receive a like protection. An increase in the tariff upon one article will, it is claimed, give an advantage to the producers of this article at the expense of the producers of other articles. Place a tariff upon a second article and then the advantage of the two which have a tariff will be increased in opposition to the interests of the producers of other articles, but if the same protection is given to all producers there will merely result a higher range of prices, which will be of no advantage to any producer. On the contrary, each producer will now be at a serious disadvantage, because he is now cut off from foreign resources and cannot make his work as efficient as formerly. Each citizen would therefore be compelled to work much harder in order to procure every necessity and comfort which he enjoys. The result would be, then, that while there was an equality in the position of producers, yet the whole effect of the tariff would be an impediment to progress, and, in the end, the productive power of the people would be diminished.

There is in this point of view a serious fallacy. A protective policy results not in general high values, 
but in the high value of commodities produced entirely by labor and capital, and a low value of the products of natural monopolies. Free-trade has the opposite effect. It tends to give a high value to the products of natural monopolies and increases the competition of producers of commodities, so that what they produce has a low value relative to the price of products of natural monopolies.

To illustrate the opposition between high values for fivished commodities and high values for the products of natural monopolies, let us trace the progress of a nation static in its consumption through the various stages of its development resulting from the increase of population. In a new country where there is free production of all commodities and but little rent paid to the owners of natural monopolies, there will be a very low price of all those products which are produced from resources which can be easily monopolized as population increases. The production of food is probably the best illustration. When a country is new the value of food is very low, while the value of commodities is high relatively to the value of food. Labor is much better paid and but little of the total production of the people passes into the hands of owners of natural monopolies. As soon, however, as population begins to increase, poorer classes of land are brought into use, and as a result there follows a higher value of food. At the same time in the production of other commodities there is a fall in value, because the competition now becomes severer than formerly. Every increase in population has two effects: it increases the 
competition of those who produce commodities and thus lowers the values of commodities which are purely the product of labor; it also creates a demand for the lower classes of land, and as a result increases the value of food-products. In both ways the part of the total production of the nation which passes into the hands of those gaining from the high price of food is increased. This change is emphasized with every increase of population. Greater competition among producers forces down the value of commodities and at the same time gives to food a higher value, until at length when population has reached its limit we have a very high value of food and a very low value of other commodities,just the opposite of what we had in the beginning, when commodities had a high value and the food had a low value. With these conditions, resulting from the development of a nation, clearly in mind, it will be seen that there is an opposition between high values of commodities and a high value of food and of the products of other natural monopolies. If a high value is given to commodities there results the necessity of low value to the products of the natural monopolies. On the contrary, if the policy of a country is such that it results in a high value of the products of natural monopolies, the value of other commodities depending for their production solely upon labor will be reduced.

A systematic protection of all producers will have the effect of raising the value of all commodities produced by them and of lowering the value of the products of natural monopolies; while a policy of freetrade, if fully adopted by a country, will create a high 
value of the products of natural monopolies and, through the increased competition which results, a low value of other commodities. It is therefore not true, as is claimed by many writers, that a systematic protection of all industries of a country will neutralize the effect of protection and make it of no avail. All those producers whose products are solely the result of labor will have an increased value, but the owners of all natural resources, which can be easily monopolized as a result of increased demand, will have a lower value. For this reason the burden of a protective policy falls upon those who are receiving their incomes from natural monopolies, while those who compete with one another upon the general market can obtain a higher value for their commodities in proportion as the protective policy has given a lower value to the products of natural monopolies.

Every commodity which is likely in the progress of a nation to become a natural monopoly has a higher value if it is exported than if the home market alone is supplied. Thus foreign trade causes the wealth of the country to be distributed in a different way from what it would be if there was no foreign trade of this kind. The classes gaining from the growth of natural monopolies have a greater share out of the total production of the nation than they would have if the natural resources of the country were used for the production of those commodities consumed at home.

The consideration of general high values as a result of protection naturally leads to another fallacy, advanced by free-traders, that the tariff is a burden upon the 
farmer. They claim that the price of commodities which farmers have to sell is fixed in foreign markets and is not increased by the action of the tariff, while the articles which a farmer has to buy has an increased value. Notice they now reason from a stand-point different from that which they took while arguing from the former position. They now assert that protection does not result in general high prices, but in a low price of agricultural exports and a high price of other commodities. Even if this were partially true, can it be inferred that there is a burden upon the farmer? I do not think so, because the effect upon farmers' profits can be seen only by considering another class of facts of special importance in determining the productivity of the labor upon a farm. The prosperity of the farmer is not determined by the price of any one crop, but by the demand of the public for all that group of products for which his land is best fitted. Free-trade may give to wheat a higher value, - at least to consumers,- - but to the farmer it destroys the value of those commodities which are not well fitted for transportation to distant markets. With the opening up of home markets, these new crops for which the soil is better fitted, but for which the soil could not be used so long as all the products of the farm had to be transported to distant lands, become the leading products of the farmer and sources from which he obtains the greater share of his profits. Here, again, the history of Western development is of special importance. In the early stages of the development of Western States wheat was the main crop, because of the necessity of transportation to distant places 
to obtain a market. The profit of the farmer therefore depended upon the price of wheat alone. But what was the condition of the farmer during this period? The fact that his land was not well fitted for wheat caused the quantity of wheat which he raised to be small even in the good years, and often his crops were complete failures. There was not the rapid progress in the development of Western States that became possible when home markets were opened up for crops better fitted for the land. The soil was so much better fitted for corn than for wheat that the gross profits of the farmers were increased by the substituting of corn for wheat. When at a subsequent period in the development of Western States a large use was made of the land to produce live-stock, the new uses of the land added to the profits of the farmer even though the profit in raising wheat was not as great as formerly.

Notice the connection between the lowering of the value of the one crop, or the few crops for which the land is used when the cultivation is primitive, and the greater gross profits which follow the use of land in many ways. With every increase in the number of products cultivated upon the land there can follow a reduction in the profit of the staple crop of the previous period and yet the condition of the farmer be improved. The better use of his land through additional crops will enable him to get an increase of profit notwithstanding the loss from the reduced value of the old crops. Suppose wheat is the first crop for which the land is used, then corn comes in as a second crop, 
finally grass as a third, and then after years some root crop is added, what effect on profits will follow each additional use of the land? The price of wheat may fall when corn is brought into use, yet the profits obtained from the cultivation of corn will be so much greater than the loss from the lower value of wheat that the farmer will be in a more prosperous condition when he makes use of his land with these two crops than if for wheat alone. When the land is used a part of the time for grass, there might follow another fall in value of wheat, and yet the condition of the farmer will be better than before, because the added profits from the use of the land for corn and grass will be greater than the loss from the lower value of wheat. In the same way the additional use of the land for roots will produce a like result. The new crop will increase the profits of the farmer and compensate for the loss from the lower value of the crop he first produced.

The labor of the farmer thus becomes more productive through the increased demand for new commodities from home producers. The interests of the farmer are in harmony with the interests of other industries, although the development of home conditions may give a lower value to some old crop for which the land has been used too much.

This same fact is shown clearly in the development of agricultural conditions in England following the introduction of free-trade. If we compare prices in England of wheat, barley, and oats for the period ending 1846 and for a second period ending 1875, it will be seen that the value of wheat has diminished, while 
the value of barley and oats has increased.* As a result the total value derived from a given quantity of barley, wheat, and oats is greater for the later period than for the former. The farmer of England has lost something upon each bushel of wheat that he produces, but this is more than compensated for by the increased price of barley and oats. Should we bring other crops than these into consideration, the advantage of the English farmers under the later period would be more clearly seen, because the prosperity of England created a demand for many articles which could not be raised to any extent at earlier periods. The price of meat and dairy products was increased fifty per cent. The losses therefore which the farmer sustained from the slight fall in the value of wheat has been more than made up in the increased value of other commodities which he can now produce and for which there was formerly but little market. The same conditions are true of every market where there is an increasing demand for a greater variety of products. The losses which the producer sustains upon the few articles demanded by persons living in a primitive way are much more than made up by the new profits which arise from the crops for which such persons create no demand.

\footnotetext{
* See the article on Corn Trade in the Encyclopædia Britannics.
} 


\section{CHAPTER V.}

NATURAL MONOPOLIES FOSTERED BY FREE-TRADE.

There are few classes of economic phenomena attracting as much attention as monopolies. Nearly every economic doctrine has been modified in some way by their influence. It is often claimed by free-traders that the policy of protection favors monopolies because it excludes foreign competition. Let us therefore examine this whole topic with care and discover, if possible, what is the real cause of monopolies, and what policy it is that favors them. To do this we must investigate the relation between the value of those commodities which can be produced without any limit and those other commodities whose products are natural monopolies.

The doctrine of value in its first form owed its origin to primitive nations where monopolies were due to governmental interference and was developed before the time when natural monopolies attracted attention. It is therefore easy to see why the early economists should assume as an ideal state a nation where there were no monopolies and where low prices would give back to consumers what it took away from them as producers. This conception is clearly stated by all the early economists, particularly by Adam Smith and his followers. At a later period there came into prominence 
a class of monopolies not based upon governmental interference, but arising from the natural conditions found in production. Under such economic conditions there is no longer any assurance that the losses which producers sustain by a lowering of prices come back again to them as consumers. Where natural monopolies abound it is more likely that low prices for commodities will result in an increased price of those products which are natural monopolies, than that the consumers of commodities will secure the advantage. The reasoning, therefore, of the earlier economists is quite defective, unless with the exception of Ricardo. That he was conscious of the limitation which must be given to his law of value and of the relation between the value of commodities and of the products of natural monopolies, is shown by the following statement: "In speaking, then, of commodities, of their exchangeable value, and of the laws which regulate their relative prices, we always mean such commodities as can be increased in quantity by the exertion of human industry, and on the production of which competition operates without restraint." Had all the subsequent economists kept this limitation in mind the later development of economics would have been more logical. Unfortunately, they lost sight of the limitation and adhered to that older theory of value which supposes that all commodities can be produced in unlimited quantities.

The doctrine of Ricardo can be modified to suit the present situation by emphasizing the opposition between the value of food and raw materials and the value of finished commodities. At an early stage in the devel- 
opment of any nation the price of food and material is low and stands in direct relation to the quantity of labor needed to produce them. At this time, also, the value of finished commodities is high ; that is, a small quantity of them will exchange for a large quantity of food and raw material. With every increase in the population of a nation not increasing the variety of its consumption and the uses of its land, less fertile lands and poorer natural resources are brought into use, and the price of food and raw material is raised. The increase of population, however, creates a keener competition among the producers of commodities, and as a result they bear a lower price. Every future increase in population adds to this contrast between the value of food and material and that of finished commodities. As all natural resources are limited in quantity, the surplus population cannot find employment upon them, but must seek work in competition with their fellows who are engaged in the manufacture of finished commodities. For these reasons a change in prices, due to increasing competition in a static society is not nominal. Any decrease in the price of commodities does not result in an advantage to consumers; the advantage is secured by those who profit by the increased price of food and material. Competition lowers wages and interest, thus taking from those not exempt from its crushing power, and at the same time increasing the advantage of monopolies to a corresponding degree.

The policy of free-trade has the same effect upon a new, progressive nation like America that would result from a large increase of its own population. The for- 
eign countries with which it must compete in the production of commodities have a lower rate of interest and wages. Home producers must therefore lower the price of commodities so that they can compete with foreign countries. The value of raw material and food rises, and a larger part of the total production of a nation goes to those who enjoy rent and the product of other natural monopolies, or who engage in the transportation or exportation of food. With free-trade poorer land of the class suitable for crops demanded by foreigners will be brought into use than would be the case if the land of our country were used only to furnish food for its own inhabitants. There will result a lower margin of cultivation and higher rents, from which all consumers of food at home will be in a worse condition than they would be with less demand for these articles of food and a smaller use of the poor land of our country.

If the growth of foreign trade increases the share which goes to natural monopolies connected with the food-supply, we cannot estimate the benefits of foreign trade in as simple a manner as is usually done. At the present time the whole problem is viewed from the stand-point of the exporters of food. The person who exports food and brings back in exchange for it certain foreign commodities makes a gain, but this gain must not be regarded as a gain to the nation, since the interest of the exporter may not be in harmony with the public interest. To estimate correctly the results of foreign trade two other elements must be considered. The onc is the loss to the public on the food consumed at home through the higher price which results from a 
greater demand for exportable food, and the other the loss our agricultural classes sustain through the reduced variety of crops. The foreign market does not create a demand for the bulky agricultural products. It is merely such light, compact articles as wheat, tobacco, or cotton, that the foreign consumer wants from America. So long as American land is used merely for advantage of foreigners the profit which might be obtained from the bulky crops is entirely lost, and this loss to the farmer must be added to the loss which consumers of food at home sustain by the higher price which the foreign demand for food causes them to pay.

At first sight it may scem strange that I should include the farmers with the losers from the exportation of food and from the high price which consumers pay for it at home. There is, however, a fallacy in regarding the price for food which consumers pay as the same as the price which the farmer gets. If the markets were local, so that the farmer has direct access to consumers, the two prices coincide. When, however, the consumer is distant from the farmer, this direct relation is destroyed. The consumer pays a high price for his food at the same time that the farmer is getting a low price. Under existing conditions America has all the disadvantages of a high price of food-by which term I always mean a high price to consumerswithout the advantages which farmers should have from it. The high price merely increases the share secured by the many monopolies standing between the farmer and the consumer.

To illustrate more clearly the connection between c d 
a free-trade policy and the growth of natural monopolies, let us assume that there are, side by side, two isolated nations, with the same natural resources, the one having a much greater population than the other. In the nation having the greater pressure of population there would be a lower value for commodities and a higher value of the products controlled by natural monopolies. As a result of this social state, wages and interest would be low and the pressure of competition would take from producers everything but a mere minimum. In the other nation with less population, there would be a much higher price for all commodities and a low price for the products of natural monopolies. Wages and interest would be high, while the value of natural monopolies would be low. Suppose now these two nations, which have so far in their development been isolated, should be thrown into commercial relations. The low price of commodities in the first nation would make it profitable to export many kinds of goods into the second nation, while the high price of food in the first nation would cause a great exportation of food from the second nation. The result would be a decrease in wages and interest in the second nation. The demand for food would be so much increased that its citizens would be compelled to pay a much higher price for it, while, on the other hand, the possibility of importing commodities from a country where their price was low would reduce the price of these commodities in a way that would cut off another slice from both wages and interest.

Suppose we take as an additional illustration two 
other nations, the one being in a static state, where there is a high price of food and material and a low price of finished commodities resulting from the pressure of population and the limited opportunities for labor which the nation has opened up to its inhabitants. The other nation is in a dynamic state, caused by the fact that the energy of the people is so great that they are opening up new opportunities for labor as rapidly as population increases. In this nation the price of commodities would be high and the value of the products of natural monopolies low. Suppose these two nations were brought into commercial relation with one another; what would be the result? Would not the great demand for food on the part of the static nation cause a higher price of food in the dynamic nation, and would not the lower price of commodities in the static nation reduce the price of commodities in the dynamic nation? Evidently there could be no other outcome. The progressive nation would be checked in its development and probably brought into a static state from the decrease in the prosperity of its inhabitants and through the great increase in the share of its produce which now goes to the owners of natural monopolies.

When the question is asked, What are the causes which check the opening up of new opportunities for labor and force a nation into a static state? we must look at the matter in a broad way before an answer is given. If all the opportunities for labor had no direct connection with one another, so that the person who opened up a new opportunity for labor would not interfere with those who utilize the present 
opportunities for labor, there would be no great obstacle to a rapid progress in all directions. This state of affairs is found in a nation having vast tracts of new land which can be had by mere occupation. As soon as the additional opportunities for labor are not to be found in new regions, but must be songht in districts now occupied, the present user of the good opportunity for labor stands in the way of the better use which the new applicant for it would make. Take as a specific example the introduction of the sugar-beet as a new crop into a country. The grower of beets cannot find new land, but must make a bid for the old land now used for other crops. He must pay as rent for this land a sum equal to the value of the land to its present occupiers. There is thus a burden upon the production of the sugar-beet hindering its increase until the production becomes more profitable than it would need to be if there were no competitors for the land.

In this way the people of a lower civilization stand in the way of a people of a higher civilization. A higher civilization cannot displace the lower as soon as the advantage from their methods of production is greater than the advantage of the cruder production of their predecessors. The new will not displace the old until the advantage of the new production is so much greater than the old as to enable the higher civilization to buy the land and other natural resources of the lower civilization which preceded them.

In the same way, whenever two nations stand in commercial rclations with one another, the people of the one country cannot secure the full advantage which 
comes from their productive agents. Before Americans can use the land of their country for their own purposes they must pay the full value of that land to Europeans. If a farm in Ireland will give a rent of ten dollars an acre producing grain for the English market, Irish consumers cannot obtain that farm to produce food for themselves unless they are willing to pay as high rent. This is the real burden of free commerce. The more progressive nations must continually pay to the owners of natural monopolies a sum equal to the full value of their natural resources to the less progressive nations with whom they come in contact. So long as foreign competition has this effect free commerce will be a hinderance to the development of the more progressive nations, and prevent that rapid advance of the whole world which might follow the best use of all resources by the most progressive nations.

Note.-It is not my purpose at present to examine into the origin and causes of rent. They are discussed in "Premises of Political Economy" and in "Stability of Prices." It may, however, be advisable to restate my position. In a static society rent is caused by the necessity of cultivating poorer lands to provide for an increasing population. In a dynamic society we also find rent, but from another cause. Better lands are coming into use, yet the increase of its productivity is not as rapid as that of the other factors in production. The most slowly increasing factor in production gets a larger share of the increase of production due to improvements than the other factors. If the productive power of a nation increases twenty per cent. while the return from land increases ten per cent., there will be the same increase of rent that a static nation would have if land poorer by ten per cent. were brought into cultivation.

My illustrations of changes in rent are taken from static societies, because the Ricardian terms are more familiar to readers. 


\section{CHAPTER VI.}

WHAT FIXES THE RATE OF WAGES.

In discussions about the rate of wages the causes which determine the rate have usually been viewed in too simple a manner. It has been supposed that there is a close connection between the productive power of a nation and the rate of wages. In fact, it is often argued as if wages absorbed the whole product of industry. If this view were correct, to decide whether or not a given policy would increase the productive power of the nation would also determine its effect upon the rate of wages. If there were no natural monopolies to absorb a large part of the return from the increase of the productive power, there would be this connection between the productive power of the nation and its rate of wages. In a nation, however, which has a large number of natural monopolies the rate of wages is fixed not by the average obtained by dividing the gross produce by the number of laborers, but by the return from the least productive opportunity for labor which the nation uses. Take, for example, a number of laborers engaged in the production of wheat. If each laborer has a farm of equal productivity, the average return of all the farms would be the rate of wages. If, on the contrary, the farms have different degrees of fertility, the rate of wages can no longer be 
determined in this manner. Those laborers who secure the most productive land must now pay a rent for the land equal to the difference between its fertility and that of the poorest land in use. Suppose, for example, there were three classes of land, one yielding thirty, another twenty-five, and the third twenty bushels to the acre. Only a part of the laborers can find employment upon the land producing thirty bushels to the acre, and hence competition between them for this land will give to the owner as rent all the difference between its fertility and the poorest land which must be cultivated. Since all the laborers cannot be employed either upon the land yielding thirty or twenty-five bushels to the acre, the poorest land in use will give the laborer emploved upon it but twenty bushels. As long as part of the labor must be employed upon this poor land, the occupiers of the better land must give a rent equal to the difference between this fertility and that of the poorest land ; that is, those that occupy the land yielding thirty bushels an acre must give a rent of ten bushels an acre, and those occupying the land producing twenty-five bushels to the acre must give a rent of five bushels an acre.

Suppose each laborer could cultivate sixty acres of land, and of three laborers the one upon land yielding thirty bushels to the acre would secure a crop of eighteen hundred bushels, the one upon the land yielding twenty-five bushels to the acre would secure a crop of fifteen hundred bushels, while the one upon land yielding twenty bushels to the acre would secure a crop of twelve hundred bushels. If the wages of the 
laborers equalled the average return from the whole land, each laborer would secure fifteen hundred bushels. Under the given conditions, however, the laborers cannot each receive that much. The laborer upon the poorest land cannot reccive more than twelve hundred bushels because that is all his land would yield. The laborers upon the other farms cannot receive more than he does because he would compete with them for the possession of these farms, and thus cause a rent to be paid by the cultivator of the best land of six bushels, and by the cultivator of the second best land of three bushels. The result is that on the three farms each laborer secures twelve hundred bushels, while nine hundred bushels of the produce of the two better farms will go to their owners as rent.

This reduction of wages, however, is not an economic necessity, but the result of a wrong policy. The lowering of wages and the increase of rent which accompanies it usually takes place with that increase of the average return for labor in all occupations. The cause of a reluction of wages lies in the passive policy on the part of the people, by which they allow the increase of population to find employment upon poorer land instead of opening up, as they should, new opportunities for labor as rapidly as population increases. The experience of the world has abundantly proved that the best opportunities for labor are not those which are first brought into use. This fact can be most clearly demonstrated in relation to the order in which land has been occupied. When a country is first opened up the settlers do not make use of the best land. They 
first seek those light soils which are fitted for wheat which can be exported to distant markets. As soon as these soils have been in a measure exploited, then resource is had to the heavier soils, which are the better soils. They are enabled to make this change through the increase of population and the growth of home markets. New crops can now be cultivated and a higher return for labor can be secured to those who occupy the land. California, for example, was at first settled merely on account of its gold, and the people did not resort to other means of employment until the gold mines were exploited, through which the return for labor was increased. The same fact is true of the resources of other States. Michigan, for example, has been stripped of its forests by the action of the same law, and the cotton-lands of the South, as well as the tobacco-lands of Virginia and Kentucky, have lost much of their fertility through this bad policy. A passive policy which allows every individual to use and exploit for his own advantage the original resources of the country necessarily leads to a reduction in the rate of wages, because the best of these opportunities will be first utilized, and as population increases the new laborers are compelled to use the poorer resources of the same kind as those already in use. On the other hand, should the nation adopt an active policy, the rate of wages will rise and not fall, since it would prevent to a large degree the exploitation of the original resources and contribute as much as possible to the opening up of new ones.

The rate of wages is directly affected also by the 
consumption of the people and the diversity of occupations. If a people demand but few things in their daily diet, only a small part of the land of the country is best fitted for these articles. As soon as population increases beyond what can be supported upon this small part of the land the rate of wages must fall, because the poorest land in cultivation will be much less fertile than formerly and the rate of wages, as we have shown, is fixed by the return upon this poorer land. In the same way the rate of wages is affected by the diversity of the occupations of the people. If there are but few occupations the increase of population must soon make use of opportunities for labor less productive than those which were first utilized. If a people be employed only in the production of iron and coal, poorer mines must be brought into use with every increase in population, and as a result there will be a gradual lowering in the rate of wages. On the other hand, if the increase in population finds employment, not in these occupations but in new ones, the additional laborers will use the fresh resources of the country and thus prevent the fall in wages. Every increase in population must result in increasing the variety of consumption and the number of occupations or a reduction of wages is sure to follow.

There is also a close connection between the rate of wages and the profits secured by the possessors of natural monopolies. Everything which increases the difference in the productivity of any of the means of production results in increasing the profits of those who own the natural monopolies. If new coal mines 
are brought into use, less productive than those now in use, the price of coal must rise, and through it all the owners of the best mines will receive a rent equal to the difference between their mines and the new mines. Suppose other still poorer mines are brought into use; there will now another increase in the price of coal follow, and through it all the owners of the better mines will receive an increased rent. What is true of coal mines is equally true of any other means of production. With every increase in the demand for raw material or for food in a static nation poorer resources are brought into use, and with it the profits of the owners of natural monopolies are increased, and at the expense of those who live from wages only.

An active policy on the part of any nation can check this tendency of competition to lower wages by changing the economic environment of the country so as to make its influence less effective. There are within the country many potential opportunities for labor which could be utilized if the obstacles to their use were removed through a more active national policy. If a nation wishes to preserve a high rate of wages for its people and keep as much as possible the increase of produce from going to the owners of natural monopolies, it must endeavor to open up new occupations for its people and turn the land of the country to new uses, so that all the people can find employment and be fed without resorting to occupations which are less productive or to crops for which the land is poorly fitted.

The commercial relations of a nation also are a de- 
termining factor in fixing the rate of wages. If two nations freely exchange commodities with one another the poorest opportunity for labor utilized in either of the nations will fix the rate of wages. To bring out this thought more clearly, contrast two isolated nations, in one of which there is an active policy endeavoring to increase the opportunities for labor as rapidly as the increase in population, and in the other a passive policy which compels the increase of population to resort to poorer opportunities for labor of the few kinds of which they are already making use. In the one country there would be a constant increase in the rate of wages, because every increase in the productive power would be fairly distributed among all the laborers through the opening up of new occupations. In the other nation there would be a constant diminution of wages as a result of the increase in rent which must follow every resort to poorer natural resources. By bringing these two nations thus far isolated into commercial relations the rate of wages in the progressive nation will be reduced, and accompanying this there will be a corresponding rise in rent. There cannot be two prices for commodities upon the same market, and the higher price of food and of all raw material in the less progresssive nation will cause a similar price to be paid for them in the other nation, and while this high price for food and raw material is paid the rate of wages will be fixed by the poorest opportunity for labor in the less progressive country. A nation cannot, therefore, adopt a system of free-trade without having its rate of wages determined by the least pro- 
gressive country with which it comes in contact, nor can it prevent that rise in the price of all articles of food and raw material which will give to the owners of natural resources all that share of the annual produce which is now obtained by the owners of natural monopolies in countries with which it has commerce. Cheap labor means a high price for food and raw material, and any nation cannot come into free commercial relations with a country having cheap labor without forcing upon itself that same unequal distribution of wealth from which the other country suffers.

Notice that I say that competition with cheap labor will lower the rate of wages of the superior workmen to the level of the cheaper laborers, and not that the wages of the efficient and inefficient will be made equal by competition. The rate of wages is determined by the objective conditions by which the laborers are surrounded. Differences in wages are determined by subjective differences in the laborers themselves, or by peculiar objective conditions that affect only a part of the laborers. Economic writers from Suith to Mill have in treating of wages followed this plan. They have regarded skill among the causes determining differences in wages and not among the causes fixing the rate of wages. The rates of wages of two countries are at a level not when all the laborers get the same pay for a day's work (that never could happen), but when the differences in wages come only from differences in the laborers' skill or from objective conditions affecting particular classes of laborers. The rates of wages are equal if the price of food and of raw 
materials, the use of machinery, and other objective conditions which determine the efficiency of natural industry are the same. When we say that the rates of wages in England and Scotland are at a level, it means that the wages of each class of workmen in Scotland stand in the same relation to other classes of workmen in Scotland that the wages of similar classes do in England, and that no workman could increase his wages by doing the same kind of work in the other country. When we say that the rate of wages in America is higher than in England, we mean that a workman by coming to America could in the same employment and with the same skill get a greater return for his labor. In other words, that the objective conditions of America are more favorable than those of England, because we are using better mines, land, machinery, etc. I do not claim that cheap labor will take from the higher workmen the differences in wages due to their skill, but it will take from them that part of their wages due to better land, mines, machinery, etc. Cheap labor is detrimental to higher classes both by taking from them the advantage of superior natural resources and by reducing the proportion of the skilled labor to cheap labor in all occupations.

Suppose in an isolated nation the skill of all the workmen was doubled. How much would the wages be increased? If free-traders are right, they would be doubled. I say the inerease would be much greater, at least threefold. By donbling the skill a twofold return could be obtained in the same mines, on the same land, and with the same machinery. More skill in the better 
mines and on the better land would throw the poorest mines and land out of use, and would also allow a use of better machinery. In this way not only would the return for labor be more than doubled, but the distribution of wealth would be changed in a way that would take from rent and add to wages. If we follow the effects of increascd skill and intelligence upon consumption, other causes increasing wages will be found. The direction of consumption would be changed to foods and pleasures, which are less exhausting of natural resources, and this change, accompanied by a greater economy in what the wages bring, would enable the nation to supply its wants without using as poor a class of mines and land as would otherwise be necessary.

By taking an isolated nation as an example we get a basis to determine the national loss from cheap labor. The evil effect of cheap foreign labor is equally great. It is more hidden from view by the circumstances which aid the free-trade fallacies. Take any case where interest or prejudice does not obscure the vision, and it will become apparent that the competition of cheap labor reduces the rate of wages, and at the same time, by forcing the use of poorer land and mines, makes the distribution of wealth more unequal. To save their favorite doctrine from comment free-traders are willing to minimize the national benefit which comes from an increase of skill and intelligence, but this policy should not keep a clear thinker from seeing that this increase has a double effect upon the product of industry through which the latter increases at a much more rapid rate than the former. 


\section{CHAPTER VII.}

THE COST OF LABOR.

Is an examination of the causes which determine the present location of national industries two leading elements come into consideration. The one is the wages paid the laborer, the other is his efficiency. An employer would not move his factory from New England to the South merely because he could there secure his workmen at lower wages. If in New England he paid two dollars a day, even as low a rate as a dollar a day in the South might be no temptation to change the location of his factory. Southern laborers are not accustomed to factory-work, nor have they that dexterity needed to use machinery at an advantage. As a result, at the end of each day the employer does not find that quantity of work done he would expect in the North, and the quality of the work may also be inferior. The Northern laborer received more pay than the Southern, yet in many occupations the efficiency of the Northern laborer is so much greater that it is more profitable to employ him. The cost of labor thus often drives out the less efficient man, even though he is willing to work for less wages.

The low cost of efficient labor is often used as an argument to show that a superior workman needs no protection from the lower wages of foreign workmen. 
In showing the causes of the industrial prosperity of England, the low cost of its labor as compared with the cost of labor on the Continent or among less civilized races is always presented as the leading element in its prosperity. Nor can it be denied that to those persons who enjoy the benefit of low prices without being themselves producers this low cost of labor is a great advantage. They have all the benefits of efficient labor without sharing in the disadvantages of intense competition. It is certainly advantageous to have others "hold their own" in a conflict for cheapness, and so long as they do it is of little moment whether they get less wages or do more work.

Yet, are we to judge in the same way if we look at the problem from the point of view of the laborer? Does not the doctrine of "holding his own" mean that the laborer should give up all claim to the natural advantages of his country and hand them over to other classes of society? If it does, certainly no one else ought to complain if the laborer is satisfied with merely "holding his own." Let us see if he should be satisfied. Suppose a country has fertile lands, fine forests, immense stores of coal and iron, should all the advantages of these national resources pass into the hands of other classes in society protected from competition, or should a part of these advantages come to the laborer in the shape of higher wages? Suppose, further, a second nation with fields, forests, and mines half as fertile, should a workman in this country have the same rate of wages as a workman of the first country? If of two workmen with the same efficiency the one 
in England works in a mine of double the productivity of the mine in France, in which the other is employed, should they have the same wages? At first sight it might seem that they should have, and upon the fallacy involved in this superficial view the free-trade argument about the cost of labor is based.

Let us, however, look at the problem in a broader way. The whole product of a nation depends upon two factors, its natural advantages and the efficiency of its laborers. If the farms and mines of one nation are better than those of another, there is added to the wealth of the first country a greater product than is added to the wealth of the second. If also the efficiency of the laborers of the first country is greater than that of the second, the difference between the wealth of the two countries would be increased. Suppose a billion dollars more than the second nation gets came to the first nation through its natural advantages and another billion through the greater efficiency of its laborers. When this sum is divided among the participants in production, to whom shall it go? We can say that the laborers can have all the product due to the increase of their efficiency, or we can decide that in addition to this they shall receive a part of the product due to natural advantages. If we give the first answer the workmen increase their wages solely through adding to their efficiency but gain nothing from the advantages of natural resources, nor do they share in the distribubution of the billion dollars' worth of goods coming from them.

Yet this is the answer free-traders give when they 
say it is good for a nation to have a low cost of labor. The cost of labor in the more productive country cannot be as low as in the other country unless the difference in the efficiency of the laborers of the two nations is exactly balanced by the difference in their wages. Under these conditions the workman in the first nation gets his increased wages entirely from his greater usefulness in increasing the product of industry, but from natural advantages he gains nothing. Suppose he migrates to the less productive country. His greater efficiency would make the difference between his wages and that of the inferior workman in this country just as great as if he remained at home. If his wages at home were double that of the workman abroad, an employer in the less fertile country could afford to give him double the usual rate of wages to work for him. He would produce twice the product and could receive twice the wages without loss to his employer. The laborer, then, of the more fertile country received just the wages he would if he did the same work in the less fertile country. How, then, does he share in the natural advantages of his own country? If a man on a good farm does a half more work and gets a half more pay than a man working on a poorer farm, does he get any advantage from the more fertile land upon which he works? How much advantage from a good mine does a miner get who does twenty per cent. more work and gets twenty per cent. more pay than does a miner working in a poorer mine? His wages depend upon his efficiency alone, and all the advantages coming from superior natural resources pass into other hands. 
When free-traders point with pride to the low cost of English labor, what does it mean? Simply this, that the workmen of England are willing that the classes in English society exempt from competition shall possess the advantages coming from the superior natural resources of England. For the sake of "holding their own" in foreign markets the laborers give up all claim to the results of home advantages. The coal miners get no more than the same efficiency would give them in the poorer mines of France or Germany. The farm hands on English wheat land get three times the wages of workmen on barren steppes of Russia if they do three times the work, but not otherwise. And the cotton-spinner can get double the wages paid in Italian mills if he will care for twice the number of spindles.

The advantage of the American over the European laborer consists in the lower value of raw materials. Wages form a larger part of the value of finished commodities and raw material a smaller part than is the case in Europe. This fact makes the cost of American labor high, but it enables the laborer to share in the benefits coming from superior natural resources.

The burden that oppresses the American laborer comes from the price he pays for the articles we export, for those we import free of duty, and for city land. It is the price he pays for bread and meat, for tea and coffee, and for house-rent that have increased and absorb so large a part of his wages. Cuban sugar and Brazilian coffee are at monopoly prices, and not 
Ohio wool or Pennsylvania iron. Cotton, woollen, silk, steel, and other protected goods are sold to laborers at a lower price than ever before. In short, the laborer, as well as other consumers, has gained wherever the national policy has been active, and lost wherever it has been passive. A passive reliance on free-trade brings ligh prices; an active preference for home production brings cheapness. The former creates natural monopolies; the latter breaks them down.

The plausibility of their theory of the cost of labor depends upon the use free-traders make of two fallacies. When they wish to show that the natural development of industry should not be interfered with they contend that natural advantages determine the location of each industry, and that its productivity will be reduced if the location is changed. Can oranges and sugar, they ask, be produced in Wisconsin and wheat or potatoes in Florida without a loss of productive power? On the other hand, when the attention is directed solely to the distribution of wealth they assume that all the productive power is due to the efficiency of the laborers. How, they now ask, can cheap labor injure American workmen when the efficiency of the American is enough greater that the cost of his labor is less than the cheaper labor of the less efficient foreigners. Certainly there is no injury if the wages of the American depends entirely upon his efficiency, but if a part of his wages comes from the use of superior resources, this part may be lost by foreign competition.

In this way, by claiming that natural resources alone determine the productivity of industry when 
national industry is viewed from a collective standpoint, and then asserting that the productive power depends entirely upon the efficiency of the laborers when the distribution of the proceeds of industry is in question, free-traders seem to have the best of both arguments. The fallacies upon which they rely become manifest only when the effects of natural resources and the efficiency of the laborers are kept in view in discussing both the production and the distribution of wealth. Join the two together and it will be seen why natural resources do not always determine the most advantageous production, and why superior laborers may lose through competition with cheap labor even though the cost of their labor is low.

It is therefore not a subsidy to laborers in a fertile country to give them more wages than the difference between their efficiency and the efficiency of laborers in less productive countries. They have a just claim upon a share in superior natural resources and this share they cannot get if they must "hold their own" with foreigners working for less wages. On the contrary, it is free-trade that gives a subsidy to people who do not deserve it. It takes the increase of wealth due to fertile fields and productive mines from workmen to whom it belongs, and gives it to classes who have some advantage through which they need not "hold their own" with less favored persons. Cost of labor cannot therefore be accepted as a criterion of the benefit derived by a nation from its industries without great injury to workmen and other productive classes which it is the nation's duty to protect and foster. 


\section{CHAPTER VIII.}

THE COST OF A PASSIVE POLICY.

Thus far the objective conditions fixing the rate of wages have received emphasis. From this point of view wages are controlled by the productivity of the natural resources which men utilize. If men want wheat, cotton, or coffee, the rate of wages cannot exceed the value of the wheat, cotton, or coffee obtained from the poorest land in use, and when more of these articles are wanted poorer lands are tilled and less wages given to the workmen. This objective-point of view, however, is not fundamental and at best gives an approximation to the actual conditions shaping production in a static nation. The direction of production is determined by the strength of human wants, and we can reach ultimate causes only by showing the harmony of a doctrine with the laws of consumption. I shall endeavor therefore to establish the law of wages I have presented by showing its accord with the new theory of value based upon the differences in the intensity of our wants. We gratify our most intense wants first, and after they are supplied we then devote our energies to the production of those things for which our wants are less urgent. Additional quantities of the same article also have very different utilities to us. A single roll for breakfast gives much pleasure; from a 
second we would derive less pleasure, and each succeeding roll would give us still less pleasure, until at last no more pleasure could be derived from eating.

Having shown the gradation of our wants, I shall show the connection between the intensity of our wants and the value the articles supplying them will have. The first roll, for example, would have a great value, because we would be deprived of a great pleasure if we did not have the roll; as we obtain less pleasure from the second roll, its value will be diminished, and the price of the two rolls cannot be more than double the value of the second roll to us. When the third roll is consumed, as the pleasure we derive from it is still less, its value will also be less, and hence if we are supplied with three rolls the value of each of them will be lower than if we had but two.

I wish to emphasize the fact that the value of any article cannot exceed the value which the least useful portion of the supply of that article has to us. If we are well supplied with meat, it will have a lower value than if we had but a small quantity to consume. For this reason the more completely our wants are supplied the lower will be the value to us of the articles supplying these wants.

Let us apply this thought to the conditions determining the rate of wages. So long as our wants are very incompletely supplied the value of labor to us will be very great, because the wants that labor can supply are intense. As our wants become more fully satisfied labor will have a less value to us, because the articles which additional labor can supply us satisfy wants that 
are less urgent. In the same way that value cannot exceed the pleasure we derive from that portion of an article least useful to us, so wages cannot exceed the value of the least useful goods that labor is employed in producing.

To illustrate, let us suppose that the labor of a community was engaged in producing four articles, two hours' work in one of which will give eight units of pleasure; in the second, seven units; in the third, six units; in the fourth, five units. If eight hours is a day's work, then four laborers, each making one of these articles, would in all produce one hundred and four units of pleasure, and each laborer's share, if the division were equal, would be twenty-six units a day. This equal distribution could not take place. If $\mathrm{A}$ is making the article that gives eight units of pleasure, he will produce in a day an equivalent of thirty-two units of pleasure; $\mathrm{B}$, who produces the article giving seven units of pleasure, will produce twenty-eight units; C, making the article giving six units of pleasure, will produce twenty-four units; while $\mathrm{D}$, making the article giving five units of pleasure, will produce but twenty units of pleasure in a day. What now must be the rate of wages? If competition is open the rate of wages cannot exceed twenty units of pleasure per day, because this is the value of the articles to consumers which $D$ produces in a day, and they will go without them rather than pay more. If $\mathrm{D}$ gets but the equivalent of twenty units of pleasure a day, $A$, $B$, and $C$ cannot obtain more, because competition will take from them all the value of their articles above 
that produced by $\mathrm{D}$. The rate of wages, therefore, will be the equivalent of twenty units of pleasure a day, although the value of the average labor of the four laborers will be twenty-six units. They will only obtain the equivalent of eighty units of pleasure, and some one else will get the benefit of the remaining twenty-four units of pleasure which comes from consuming the articles the laborers make.

The result, of course, would be different if each man worked for himself and supplied all his own wants instead of making exchanges with his neighbors. If each of the laborers worked two hours producing the first article, then gave two hours to the second, then two hours to the third and two to the fourth, they might obtain for themselves an equivalent of one hundred and four units of pleasure, which is all their labor has created. When, however, labor is divided, each man devotes his attention to the production of some one article. One laborer is producing an article upon which the community places a high value, a second devotes his energies to producing an article regarded as less useful, while some of the laborers are at work upon articles which the community do not esteem very highly. With such a division of labor the rate of wages must be so low that it will not exceed the value, to the community, of the day's work supplying the least urgent want the community are gratifying. Some of the laborers get their wages entirely from the value of articles supplying these least urgent wants, and all the other laborers through competition will have their wages reduced to a level with their less fortunate 
fellows who supply the least urgent wants. Wages, therefore, must fall when the community can get commodities satisfying less urgent wants, and whatever forces a part of the laborers into occupations supplying less urgent wants will lead to a reduction in the wages of all laborers.

These facts, it seems to me, furnish an excellent explanation of the theory of over-production to which so much attention has been given and for which so many explanations have been furnished. Every great invention leads to a displacement of laborers. There is so great an economy of labor introduced into the production of many articles through machinery and other improvements, that only a part of the former laborers can be employed in the old industries. Some of the men must seek employment in new occupations. They must supply new wants which thus far have not been gratified by consumers. These new wants, however, are less urgent wants than those now supplied, and hence the value to consumers of the articles supplying them is less than the value of articles supplying the more intense wants. The value of the articles supplying these new wants being less, the wages of those who produce them must be lower than their wages would be if they were engaged in the old occupations, and the wages of all other competing laborers will be reduced to the value of a day's labor in the articles supplied by the new industries. In this way a series of improvements leads to a fall of prices and hard times. There is a transference of the benefits of the improvements to the classes exempt from competition. Although 
the average return for labor has been increased by the improvements, yet the rate of wages has been lowered, thus giving a double gain to those not competing on equal terms with their fellows. Just as the occupation of poorer land raises rent and lowers wages, so will the transference of laborers to occupations supplying less urgent wants increase the advantages of the privileged classes and lower the rate of wages. Even if new wheat lands are as productive as the old land, the wages of its producers will be reduced if the additional wheat supplies the desire of consumers for bread more fully than before.

Improved production results not merely in an increased production of the cheapened articles; it also leads to a varied production, through which the community has some of its less intense wants gratified. The consumption of cloth does not increase proportionately with the reduction of its cost, and hence a part of the laborers must be transferred to occupations supplying less urgent wants where the value of their labor will be less than formerly. Suppose, as an illustration, the rate of wages in the old occupations was a dollar, and the value of the product of a day's work in the new occupations ninety cents. Suppose, further, there was an increase in the productive power in the old occupations of twenty per cent., and that the increased demand for these articles through the reduction in their cost was enough to employ one-half of the laborers who were displaced. Nine-tenths of the laborers would now produce eight per cent. more than all of them did before the improvement in production. It would 
seem, therefore, that an increase in the rate of wages would take place. But this is not possible, for onetenth "of the laborers are not einployed, and they must seek employment in the new occupations where the value of the product of a day's work does not exceed ninety cents. So long as one-tenth of the laborers must work for ninety cents a day, the other ninetenths, instead of getting the increase of wages that might otherwise come to them through the increase of productive power, will also through competition find their wages reduced to ninety cents a day.

In this way improvements at first tend to reduce rather than increase the value of a day's work. There are always a number of new wants not quite strong enough to make the pleasure of consumption equal to the cost of supplying the want. The price the public desires to pay is not sufficient to give a fair rate of wages. From the increase in population, and also from the displacement of labor through improved production, there is constantly a surplus part of the laboring class which must seek employment in supplying these new wants. The only question is, Shall we aid or retard this movement of laborers into new occupations? So long as they are not encouraged by the state, the wages in these industries must for a time at least be very small. There are so many expenses connected with the opening up of a new industry that the wages obtained from it must for a long time be much below the level of other industries. In all these same ways a relatively larger proportion of the whole labor of the community must go, and however much the produc- 
tiveness of American industry is increased through improvements, there will be a tendency towards a lower rate of wages so long as a part of the laborers are forced into these new occupations, where, for a time at least, their remuneration will be small.

The readjustment of our wants to our present economic conditions will in the end straighten out this difficulty, but until then wages must be relatively low, and a large part of the proceeds of industry will pass into the hands of those freed in some way from the depressing effects of competition. Wages can be restored to their former level or forced above it only by the increased urgency of these new wants, but this change cannot take place until the consumption of the new articles becomes habitual. In time the new wants will become of equal urgency with those now supplied, and only then will the injurious effects upon the laborers be removed. So long, however, as the national policy is passive and nothing is done to aid the transference of laborers to new occupations, the course of prices and of wages will be as I have indicated. The cost of the passive policy to the people is measured by the loss of labor aud capital during this period of transition, while there is a great difference in the urgency of the various wants which are gratified by the articles produced by laborers. A passive policy prevents an increase in the opportunities for labor as compared with population and is thus the cause of the crushing effects of competition. There is only a small surplus of laborers without remunerative occupation, but these few have a depressing effect upon wages. Change 
the relation of population to opportunities for labor and wages will rise rapidly, and those natural monopolies which result from a passive policy and from the increase in the pressure of population will lose their value.

To shorten the hours for labor so that the whole laboring population could be employed in the old occupations might prevent a fall in wages, but it would also prevent the growth of the new wants. They cannot increase in strength until they are regularly supplied, and in this way shorter hours would delay the ultimate remedy, through which alone there can be a permanent solution of our labor difficulties. A better solution of this difficulty would come through the cheapening of the articles gratifying the new wants at the expense of the old stable wants which have now a high value to the public. An active policy must always in some way further this solution, and thus make the whole society bear its share of the burden coming from the transference of laborers to new occupations. A national policy is not efficient unless it furnishes conditions through which opportunities for labor will increase as rapidly as population increases. A passive policy, on the contrary, throws the whole burden of the readjustment of society to new conditions upon the laboring classes. More than this, it makes the burden many times as great as it might be, since probably not more than one-tenth of the laborers are seeking employment in the new occupations whose products are not as yet valued highly enough by the public to pay fair wages. Free-trade would have a 
very detrimental effect upon this readjustment to new conditions, because it would force us to wait until Europe, as well as America, changes its consumption in a way that will allow all the laborers to find a profitable employment. As a consequence the length of the period of transition to new forms of consumption is greatly extended and its burden to the laboring classes increased. In so far as we have reason to believe that American society is in a more dynamic condition than that of Europe, and that it will by itself move along more rapidly in the only way that can lead to an adjustment of opportunities for labor to population, just so far do our interests demand that we isolate ourselves from European conditions as much as possible, in order that our society can adjust itself to the new conditions more rapidly than it could if we were in close commercial relations with the more static nations of Europe. 


\section{CHAPTER IX.}

WHERE FOREIGN COMMERCE IS A NATIONAL LOSS.

Among the various countries there is a great variety of natural advantages. The soil, climate, geographical position, and mineral resources of no two countries are the same. This country has advantages for the production of grapes and oranges, but no coal. The second has good wheat land, but is inferior for fruit. The third is adapted for corn and tobacco, but not for sugar or rice. Besides these physical differences there have developed among the inhabitants of these countries a diversity of tastes, habits, and intelligence which give them aptitudes or inclinations for different occupations. Upon these differences in nature and men, whether original or acquired, all foreign trade depends. Were it not for them we would build no long railroads, dig no ship-canals, nor have our seas covered with a fleet of ships sailing to and from every part of the world.

This commerce may be divided into three classes, according to the causes which make the trade profitable. First, there are exchanges which take place between nations with such differences of soil and climate that the products of the one either cannot be grown in the other, or, at least, would be grown under such natural disadvantages that the same labor would be much less productive, while in its own products the second country has a like advantage over the first. England, for 
example, is a better wheat country than Cuba, while Cuba can produce sugar at a much less cost in labor than England. If trade between them should cease both countries would have to expend more labor to get the same quantity of wheat and sugar. To shut off this exchange of products would be a waste of labor for which there could be no compensation.

In a second kind of trade the advantage is merely relative. Suppose a week's work in Cuba would give sixty pounds of sugar or fifteen pounds of coffee, while in Brazil the same work would produce seventy-five pounds of sugar or twenty-five pounds of coffee. In this case Brazil has an advantage in raising both sugar and coffee, yet, if commerce were free there would spring up between them a trade in these articles. Brazil has an advantage in the production of both articles and a relative advantage in the production of coffee, while Cuba is at a disadvantage in the production of both articles yet has a relative advantage in the production of sugar. A pound of coffee in Brazil would buy only three pounds of sugar, while if taken to Cuba it would buy four pounds. A trade profitable to dealers would thus spring up, growing out of the relative cost of the two articles. In case the commerce should be shut off, would both nations suffer permanently, or could they adjust themselves to their new situation in a way to compensate for the decrease of foreign trade? This is a matter of dispute.

A third class of exchange arises from differences in the inhabitants of various parts of the world. The skill, strength, and intelligence of the workmen in one 
country differ greatly from those of any other, through which their inclination or ability to do work of a given kind is very marked. Each nation has through historical conditions or natural advantages acquired a knack to do a few kinds of manual labor with more efficiency than the laborers of other countries can do it. In this way China has become noted as a producer of tea, Italy of silk, France of wine, Portugal of fruit, and England of iron and cotton goods. Out of these conditions a trade springs up between the various nations caused by the relative advantages they have for the particular articles in which their workmen are most efficient. In the case of this commerce also the question is asked, Would the nations suffer an irreparable loss if the trade should cease? Here again the answer is a matter of dispute.

The central point, then, in the discussion about foreign commerce lies in the utilization which a nation should make of its relative advantages over other nations. The free-traders contend that trade based upon the relative advantages of different nations is always valuable and leads to the national prosperity of both nations. A protectionist would discourage these exchanges and encourage home production, thinking that national prosperity can be realized only by the best use of all national resources coupled with the fullest development of the industrial qualities of the people.

The chain of reasoning used by the free-trader is a simple one. Exchanges based upon relative advantage are a source of profit to the individuals engaged in the trade, and what is a good policy for individuals cannot 
be a bad policy for the state. The reasoning on the other side is longer and less direct, yet it reaches the root of the matter. National prosperity is a much larger and more complicated problem than that of the individuals who form the nation at any given time. The nation is not merely a group of units whose prosperity can be determined by observing contemporary facts. National prosperity depends upon the natural laws regulating the supply of raw material and upon the industrial possibilities of the people. A progressive nation must see not merely that its present inhabitants have a profitable trade, but that the latent qualities in men and land are gradually drawn out. The effect of foreign trade in bringing the nation prematurely into a statio state also demands investigation, since the endeavor to keep the people dynamic is as much an element of a good national policy as is their present prosperity.

From this point of view a prominent error of freetraders results from their lack of knowledge of the conditions of agricultural prosperity. They always talk of some one use of each tract of land as though it were a machine made for a particular purpose. This tract they regard as good wheat land, that as good for pasture; another is good for corn, while the next is good for rice, and the fifth for sugar. This method of reasoning about land was introduced by Ricardo in all his discussions and has been accepted by his free-trade followers. Yet in reality this conception of land is as abstract and far more false than that of his economic man, which the later development of economic science has discarded. The conception of good wheat land or 
of any other land suited to some single use must be displaced by a better one before an intelligent discussion of land problems is possible. The true conception of land is that of a productive instrument suited for a group of crops. Any land is poor land for one crop. It becomes better land through an increase in the variety of its products, and is superior land only when a suitable rotation of crops brings out all its qualities. The course of foreign trade may make the use of land for a single crop more profitable for a time, yet the gain to the owner is at the expense of the productive qualities of the land. Free-trade thus prevents a well-balanced development of the group of industries which will make the most of the land.

Suppose that of two nations similarly situated in relation to the world's market the one allows land-owners to follow the line of greatest present profit and put the land to some one use for which the relative advantage is greatest, while the other discourages any trade which prevents the use of the land for all crops for which it is especially fitted. The land of the first nation would gradually become exhausted through continued cultivation of one crop, while that of the second would become better land through the development of its latent qualities by a suitable rotation of crops. Is it not plain that the second nation would have the greater population and wealth at the end of a given period?

We cannot in this way, however, measure the full value of the advantage of the second nation. Within a given area where a given crop has a relative advantage much of the land will not be suited for this crop. 
While Illinois was used merely for wheat, from a fourth to a half of each field was not tilled because it was not suited to wheat. The cultivated area of the State thus formed but a fraction of the whole area ; while at a later period, when corn and grass became leading crops, a large part of this unused land became the best land. There was a revolution in the estimation of land throughout the whole State, by which the better land from the old point of view became the poorer from the new. In this way the use of the land for purposes for which it is at a relative disadvantage not only makes all the land better than if used for any one crop for which it has a relative advantage, but also greatly increases the area of cultivated land.

Again, the relative advantage of a crop depends upon the distance of land from market. The farther the land is from market the greater the relative advantage of wheat or other crops easy to transport. A home market increases the advantage of bulky crops like corn and grass. It is impossible to tell what crop has the relative advantage until the distance from market is known. Taking Illinois again for an example: so long as England was the only market, wheat was the sole crop. As soon, however, as the growth of American cities and the opening up of railroads gave a home market for corn and grass products, wheat immediately ceased to be grown in Northern Illinois. Even the farmers now buy it as regularly as they do their sugar or coffee. Why? Not because England does not still want wheat, but because local markets allow the land to be used for what it is better fitted. 
Free-traders forget that the prosperity of this country depends upon corn and grass, for which the market is local, and not upon wheat and cotton, which have the relative advantage in foreign trade. The North would be as poor as the South and its cities as small if the land of the North were used for wheat as that of the South is user for cotton. Had our whole nation followed the lines of relative advantage advocated by free-traders, our country would be divided into three parallel belts, used for cotton, tobacco, and wheat. The two sections fitted for cotton and tobaceo, by following this policy, are poor and under-populated. The third section, by following the lines of absolute advantage more closely, has kept the nation prosperous and made it populous and wealthy.

It is the use of all absolute advantages that has made other nations prosperous, and England forms no exception to the rule. England has a relative advantage in her coal fields, while Sweden and Spain have the same advantage in their iron-beds. But did England ever advocate the closing of her iron mines so as to gain the relative advantage she could get by exchanging her coal with the iron ore of other nations? She also has a greater advantage in the production of cotton goods than of woollens ; yet which of her statesmen has wished her woollen-mills to close, believing that the increased gains from her cotton-mills would more than counterbalance the loss from woollen-mills?

Peculiar advantages in one article, instead of being the cause of national property, as free-traders would have us believe, are usually a hinderance to progress. 
The inhabitants of a country confining their energies to the utilization of some one advantage neglect other industries to a degree that they would not do if the advantages of several industries were about equal. The effects of cotton cultivation in the South is a good example of the national detriment which flows from too great an advantage of one crop. Had wheat in the North the same advantage that cotton has in the South the development of the North would have been greatly retarded if not prevented. Fortunately for the nation Western lands were really poor wheat lands, so that the relative advantage for wheat in foreign markets was to a large degree counterbalanced by the superior productivity of the land for corn and grass. As a result even a moderate tariff changed the advantage from wheat to corn and grass, and thus promoted a natural development in the West. The advantages of cotton in the South and tobacco in Virginia were so great that this tariff could not place on equal footing other crops not needed for Europe, and as a result the one crop of each section wore out the land and kept the people in poverty.

The same fact shows itself in other countries. Cuba would be more prosperous if she were less fertile for sugar, for then Spanish misrule would not be possible. Coffee has not made Brazil or Java rich and prosperous countries. If a blight upon the grape-vine should force the people of Portugal to use their land for a variety of uses for which it is well fitted, the loss of relative advantage in grape cultivation would be a national gain. And the history of England bears tes- 
timony to the same truth. At an early period the sheep industry paid so well that the quantity of cultivated land and the demand for labor were greatly reduced, thus checking the progress of the nation. The increased number of sheep did not come from any especial advantage of the sheep industry in England. It was Continental disorder that prevented the keeping of sheep elsewhere. Thus the fact that England was far enough in advance of other nations to protect property in country districts checked the growth of population and wealth by giving a relative advantage to sheep-raising. Its people suffered solely because of the relative advantage of an industry which could employ but a fraction of the whole population. The advantage in various industries which might have been secured to Eugland through its internal peace was lost because of the relative advantage of wool-growers.

If national prosperity cannot come from the use of a single advantage, still less can it be secured by encouraging a trade with inferior races or by the utilization of the advantages arising from contact with inferior men at home. Put men of superior and inferior ability in commercial relations and exchanges will take place which would not occur if the standard of living for all was the same. The skill, intelligence, and habits of each race and individual are the results of social environment. An individual may not be to blame for a lack of superior. industrial qualities, but the nation of which he is a part is responsible. Every industrial quality may be acquired if the nation encourages its development. There are 
no marks to distinguish the English from the Italian workman but those due to the historical development of the two nations. Place the Italian nation in the social environment of the English and they would soon be as efficient. No progressive nation can accept any industrial deficiency of its people as final. Any trade arising out of such a deficiency is detrimental to the individual as well as to the nation.

If a nation can find no compensation at home for the loss of foreign commerce based upon relative advantage, then each family also is better off to have poor and ignorant neighbors than to have those of equal intelligence. In every exchange with such neighbors the family gets as great a relative advantage as the nation does through its trade with less intelligent foreigners. Which lawyer has the greater income, he who has his equals as clients, or he who works for his inferiors? If an intelligent physician has three times the efficiency as a physician and twice the efficiency as a workman as those about him, will he have a larger income than if he were in a community where every man had his intelligence? The more intelligent community would make so much better use of all its resources that the average income would be raised. The physician in the first community would be relatively better off than his less fortunate neighbor, but in an absolute sense he would have less to enjoy than if he were an average man in the second community. A farmer also might get his corn more cheaply if his neighbors, using a poorer system of cultivation than he does, do not drain their land or raise live-stock, yet 
cheap corn could not compensate for what he suffers through the lack of intelligence of these neighbors. Their productive power would be so small that population would be scattered, and many of the advantages of large centres of trade would be unavailable to him. He would also be deprived of good roads, schools, and churches. He might continue better off than his neighbors and yet have much less than if he were an ordinary citizen of a more intelligent community.

The advantage we get from neighbors is not merely from their producing certain articles more cheaply than we can. If they consume what we consume we can buy more cheaply. The price of articles is reduced by an increase of demand, as well as by cheaper labor. We make a gain in commerce both from the intelligent and unintelligent; but the gains we secure from the former are far greater than those derived from the latter. In dealing with the latter the percentage of profits may be higher, but the gross profits will be less.

In foreign trade the same simple facts are decisive, although its evils are much more obscured by complicated conditions. Americans are very free in expressing the opinion that the military system of Germany reduces its productive power and is detrimental to the world's progress, yet this same military system has given to its people those characteristics which make our present trade with Germany so profitable. We must, then, contradict ourselves by saying that our prosperity depends upon the continuance of what we believe to be detrimental to Germany, or admit that the present trade with Germany could diminish or even cease with- 
out any permanent loss to ourselves. And the same argument applies to the commerce of other nations. Are we prepared to affirm that Italian ignorance and Turkish oppression are advantageous to America? If not, then we must admit that we would not lose if foreign trade based upon relative advantage were cut off, because this trade is of its present nature as a result of the ignorance and oppression of other nations. Without this trade we would develop new lines of commerce with all these nations where the advantage is absolute and in which our labor as well as theirs would be more productive.

Picture for a moment an ideal civilization where the best use is made of all the land and where all the industrial qualities of its inhabitants are fully developed. The distribution of the population would not be determined by historical and social considerations, but by the productive qualities of land and of natural agents. If one region was more fertile than another, population would adjust itself so as to give that region a population proportional to its productive power. Relative advantage would be no longer a cause of exchange, where the adjustment of population to natural advantages is complete.

Suppose such a society be brought into contact with a typical nation of the present in which the inhabitants have a defective development resulting from past conditions, and in which the land is used for some one crop for which it is not best fitted, what would be the result in the ideal society? Would not the relative cheapness of the few articles which the people of the inferior nation 
make to an advantage disturb the equilibrium of the ideal society, so as to offer a premium for the growth of a class of men in it whose industrial qualities were not harmoniously developed? Would not also the single use to which the inferior nation puts its land disturb the values of agricultural produce, so as to offer a like premium for using of the land of the ideal nation in a way detrimental to its greatest productivity? Most assuredly it would. Every man lacking in any industrial quality exerts a pressure forcing some other man into a one-sided development, so that his industrial qualities will supplement those of the first. Every field used for some one crop or with a defective rotation of crops exerts a like pressure, forcing other fields to be used for other crops more frequently than is in harmony with their best use. The productive power of every nation is much below what it might be if the disturbing power of inferior men and badly-cultivated land were removed. The chief source of this disturbing power lies in the endeavor to utilize relative advantages in foreign trade.* These gains are of the same nature of land exploitation at home. The temporary interest of a few is given more consideration than the permanent good of the whole. A sound national policy must cut off these sources of profit to individuals and make it for their interest to co-operate for the good of the whole.

* "The produce of the whole world would be greater or the labor less than it is if everything were produced where there is the greatest absolute facility for its production."-J. S. Mill, Book III., C. 17, Sec. 8. 


\section{CHAPTER X.}

OBSTACLES TO ECONOMIC PROGRESS.

To determine the best policy for a nation it is necessary to examine into its environment and see what conditions aid and what obstacles oppose its growth. Whether or not an individual advocates an active or passive policy on the part of the nation in reference to the obstacles which stand in the way of economic development, depends largely upon his ideal of economic progress. There are two ideals which stand opposed to one another, and every writer, either consciously or unconsciously, adopts one of them.

In the first place there is the static conception held by all the consistent advocates of a passive policy on the part of governments. This ideal supposes that the best opportunities for labor-that is, the best lands, the best mines, and other resources-are used first, and that as population increases poorer natural resources must be utilized to give employment to the additional population. In this way the average return for labor is reduced, and the society finds itself crowded into a narrower economic condition with every increase in population. This conception might be well compared to an isolated lake which gradually fills up with every increase in the quantity of water put into it. There 
will be a constant rising of the surface but without any movement of the water in any direction.

The other ideal opposed to this is a dynamic one. It supposes that the individuals of a society are constantly changing with their environment, that they have new wants arising out of their new conditions, and thus there are continually opening up to them new opportunities for labor better than those they first put into use. In this way the society gradually progresses out of a poorer economic condition into a better one, and a gradual increase in the average return for labor comes with every change in the economic environment. This progress, however, is not regular. A series of obstacles hindering economic progress must be removed one by one in order that society can develop in an orderly manner. As a society presses against an obstacle standing in the way of its progress, the phenomena, so prominent in a static society, appear of a gradual diminution in the average return for labor and a more unequal distribution of wealth. This state of affairs, however, increases the interest of society in having this obstacle removed, and finally the inducement becomes so great that the obstacle is set aside. Then we have a period of increased prosperity until some new economic obstacle is reached, and then the same course of events is gone through again.

This ideal of social progress might be well compared with a river cutting its way to the ocean after some geological change has forced it to take a new course. 'The water flows downward into a basin, which gradually fills until the water has reached the height on the 
lower side. Then a channel is cut through this obstacle and the level of the water is lowered. Passing on, it fills the next basin until it reaches the height enabling it to cut its way through the second obstacle. Thus the progress of the river would be checked by a series of obstacles retarding its progress for a time, but not of sufficient strength to prevent the gradual cutting of the course of the river through all that opposed it so that the water can flow into the ocean beyond.

In presenting this conception of social progress, I want to bring forward more clearly the economic conditions which make many obstacles for society to overcome and retard its progress in a somewhat similar manner to that of the river I have just described. Just as the river reaches a lower level after breaking through an obstacle, so a society will find better opportunities for labor with each economic obstacle it overcomes. The poor resources it first used will be abandoned for the better ones it finds as it progresses.

Americans are making poor use of their country. We are not using our land for that for which it is best fitted, nor are we cultivating it in a way that will make it most productive. Our material resources on all sides are being wasted and many of them are not at all utilized. Hence it cannot be said that we have begun with our best resources, and that our development will be in accordance with the concept of social progress corresponding to that of a static state in society. We are, I might almost say, making as poor a use as we can of our resources, and hence the possibility lies before us of making great progress in every direction. But what 
stands in the way of this progress? A series of obstacles which the American people must surmount one by one as they advance along the course of their civilization.

I think no one will deny that the past development of the American people has been the gradual surmounting of a series of obstacles. The soil, when first occupied, required immense efforts to bring it into a productive condition, and when it was made productive there were serious obstacles to overcome in opening up roads to bring this produce to the markets of the world. When these agricultural needs were satisfied then arose a need to develop the manufacturing interests of the country. The cotton and woollen industries in the beginning had serious obstacles to surmount which for a long time retarded their successful development. Then came the period in which the obstacles to American progress lay chiefly in the cost of transportation from the interior to the coast. These obstacles have been at length successfully surmounted by the development of our system of canals and railroads; but there remains before us yet a long series which will require an active policy on the part of our people to surmount without creating that unequal distribution of wealth which shuts out all social progress.

In the beginning we had infant industries to protect and develop, because we lacked those social conditions which are necessary for the successful prosecution of the textile and iron industries. Infant industries are, however, something that a nation will always have as long as it remains in a dynamic condition. If a people 
become static and wish merely for the same few articles that their ancestors had, then of course there are no new industries to develop. With every change in the economic conditions of the country and with every growth of variety in the tastes of the people, new industries are called for to supply the demand of the people for new articles. These industries need the same protection and encouragement that those developed in the past received. We cannot have an orderly, consistent development of our country and its resources unless the national policy is so directed that it will encourage the introduction of new industries with every change in the tastes, habits, or environment of the people.

There is more than this to keep in mind. Many of the present wants of our people, now obtained from foreign lands, can with economy be supplied by home production. Our climate and soil are well fitted for the production of many articles now coming from foreign countries, and our undeveloped mineral resources can supply us with many metals for which we are now dependent upon foreign lands.

I shall illustrate my point with several specific examples which apply especially to the undeveloped condition of the South. Our Southern States lie in a semi-tropical region and are well fitted for all those crops which we secure from similar regions abroad. The reason why these crops are not grown at lome lies solely in the social condition of the South, which has almost compelled the people to confine their industrial activities to the production of cotton and tobacco. These 
social conditions have now passed away, and there is no reasol, why a great variety of industries cannot be successfully prosecuted in the Southern States as soon as the obstacles to their introduction are set aside. An example of this we find in the production of tea. There are many portions of the South where tea can be produced with as little labor as in any part of China. The obstacle lies wholly in the ignorance of the Southern people with respect to the proper methods of cultivating the tea-plant and in the lack of encouragement which the nation should offer to those who would endeavor to produce tea. Were we willing to pay the additional price needed to overcome the obstacles to the introduction of tea-culture in the South, we should soon be enabled to produce it with as little labor as in any part of the world.

A second illustration is in the production of raw silk. No part of the world can surpass many portions of our country in the favorable conditions for the production of silk. Here again the obstacle to the successful introduction of this industry lies in the series of temporary obstacles which must be overcome before the industry can be prosecuted with success. The temporary price must in the end be paid, and when the American people are willing to pay this price an immense increase of home industry will follow to the advantage of the whole people.

The present condition of Florida is perhaps as good an illustration of my point of view as can be found. Florida and Cuba are under the same climatic conditions. They are in the same latitude, surrounded by 
large bodies of water, which maintain an even temperature, and thus enable all those semi-tropical plants to develop which are now in so great a demand. Cuba, however, has the advantage of Florida in one respect, which has made it one of the most productive regions in the world, and the lack of which has made Florida a wilderness. Cuba has a natural system of drainage, and its waters flow freely and easily into the ocean. Florida, from its geological formation, has a series of obstacles stan dingin the way of the flow of the water into the ocean. Remove these obstacles, drain the whole surface of Florida, and our dependence upon Cuba would cease. We could then produce our sugar and tobacco in Florida, and at no greater cost than it is now obtained from Cuba. We might even, without exaggeration, make a still stronger statement and say that all these articles could be produced at half their present cost in Florida if it were brought into a condition to be successfully cultivated. The uncivilized condition of Cuba prevents the introduction of machinery and keeps the social condition of the people at so low a state that they do not have half the productive power that a more civilized race would have. With the stable government which Florida now has all those unsatisfactory conditions which exist in Cuba could be avoided, and as a result the productive power of Florida would far surpass that of Cuba, and its usefulness to the whole country would be correspondingly greater. The far West with its arid plains presents another series of obstacles to progress. This vast region will be comparatively useless to the American 
people until a comprehensive system of irrigation is made a part of our national policy.

The obstacles to the successful development of agriculture in the South and far West stand out more clearly than do those of other sections of our country, yet in reality they are not more important.

American soil is poorly fitted to the growth of grain, and the obstacles to the successful cultivation of other crops must be removed before our agriculture can become as productive as it should be. The productivity of root crops in our country is so great that their development is a condition of agricultural prosperity. The present breeds of live-stock need also to be developed and modified so that they will become better adjusted to American climatic and economic conditions. Our cattle, sheep, and hogs are not American animals, but are recent importations from foreign climes. They are accustomed to live upon those products which are fitted to European conditions, and before they can become most advantageous to us they must develop characteristics which will fit them for American climate and for feeding upon those crops most suitable to American soil.

The removing of obstacles can be well illustrated by the growth of the beet-sugar production in Germany. German conditions are not as well adapted to the production of sugar as the climate of more southern regions, but Germany is the centre of a great civilization, and its people were not satisfied with the high cost of the sugar they obtained from southern regions. This high cost was a result of the crude processes in 
the manufacture of sugar which were in use in all cane-sugar producing countries. Had these regions been fully civilized and their industries been highly developed, the beet-sugar industry of Germany could not have succeeded. Under existing social conditions, however, we have a contest between efficient labor on the part of the German people and favorable climatic conditions on the part of the cane-sugar-producing countries. In this contest the efficient labor of the German people gives them a supremacy, and as a result we have a lower price of sugar than we could have had if we had relied solely upon the semi-tropical regions inhabited by half-civilized peoples.

There is another fact in this connection still further illustrating my point of view. The beet when first cultivated in Germany contained but a small percentage of sugar. It took fifty years of careful scientific investigation and experiment before a beet could be produced which contained a large percentage of sugar and at the same time was fitted to the climatic conditions of Germany. There were, however, more obstacles to surmount than these. It was found that a beet which would yield a large percentage of sugar in one locality, if transferred only a short distance upon other soils would often produce a much smaller quantity of sugar, or the sugar might be in such chemical combinations as to make its extraction unprofitable. Hence a new series of experiments were necessary for each locality, and the extension of the cultivation of the beet has followed the gradual surmounting of these obstacles in each locality by careful scientific investi- 
gation. If the American people would take half this care to domesticate new crops they would be as well rewarded.

Thus far I have treated merely of the obstacles to the development of natural resources. There is, however, another series of obstacles of even greater importance which must be surmounted before the industry of the American people will be as efficient as it might be. Not only must Americans develop American resources, but Americans must adjust themselves to American conditions. We are at best but recent emigrants from forcign countries, and our tastes and habits are largely the results of the European conditions in which our ancestors lived for so long a time. When our forefathers came to America they found themselves in a new economic environment, and since then we have been slowly adjusting ourselves to it. Yet this progress has been very slow, because the customs and habits which they brought with them were the result of ages of slow development and cannot be changed in a single generation. American people in the end must live upon those articles for which American soil is most productive, and must cease to consume in as large quantities as they do those articles for which our soil is but poorly adapted. New articles of diet will find their way into use, and habits and customs will develop which will make the American of the future a man utilizing all the resources of our country.

American history furnishes many illustrations of the evil effects of the passive policy pursued by our nation through which the obstacles to economic progress were 


\section{THE ECONOMIC BASIS OF PROTECTION.}

not overcome as rapidly as they should be. If new resources are not opened up with the increase of population poorer resources in conjunetion with those now in use have to be resorted to by the additional population, and in this way there is a great waste of capital and of productive power. Such an economic waste presents itself in the period between 1825 and 1840 . At that time all the better resources of the Eastern States were developed. The question then was, Shall the additional population be aided in its progress towards Western States whose resources are not in use, or shall this additional population find employment upon the poorer resources not yet developed in Eastern States? A national party was active in endeavoring to open up the resources of the Western States, but unfortunately for our nation it was defeated, and the party favoring a passive policy continued in power. What was the result? The additional population, instead of going to the West as it should, brought poorer lands in every part of the East into cultivation. Immense quantities of labor were expended in preparing this land for cultivation by removing stones, cutting down forests, opening up roads, and other needed improvements which are necessary for agricultural prosperity. During the next twenty years, however, the obstacles standing in the way of the movement of population into Western States were overcome, and the extra population passed rapidly and easily into the newer sections of the West. Their labor was so productive in the West that they underbid the farmers of the East and forced the price of agricultural produce 
to so low a point that a large part of the Eastern farms could no longer be cultivated with profit. To a large extent these farms have gone out of cultivation, and as a result the immense quantities of labor and capital which were needed to bring them into cultivation have been a national loss.

Suppose instead of allowing all the quantity of labor and capital to be used up in bringing the poorer lands of the East into cultivation a mere fraction of it had been expended in opening up the West to Eastern settlers twenty years before it was, would not the result have been of great advantage to the whole American people? Would not all that waste of labor and capital have been avoided, caused by bringing into cultivation the poorer lands of the East only in the end to go out of use again? 


\section{CHAPTER XI.}

THE FUTURE OF RAW MATERIAL.

IN the production of raw material we have the last part of a long struggle of man with nature. Elsewhere civilized man is now supreme and has cast off the bonds that held him to natural production. In primitive nations production is confined to localities where nature does so much that crude ignorant men can do the rest. In the production of finished commodities this influence of location is reduced to a minimum. The extensive use of capital, skill, and intelligence have freed modern nations from the primitive forms of production which confined each industry to particular regions where nature gave the most assistance. Water-power is no longer essential to national prosperity, steamboats are displacing sailing vessels, linen is no longer sent to Holland to be bleached, and railroads have given to the interior of continents the advantages formerly confined to the sea-coast. In short, the advantages of localities having particular combinations of natural forces or agents have been greatly diminished, if not entirely lost. Man is still dependent upon natural forces, but not as much as formerly upon the natural features of given localities or regions. Every new utilization of natural forces decreases our dependence 
upon those productive processes in which natural production is advantageons.

Before our civilization reaches the goal towards which it is advancing, this dependence of man on natural production must cease in the case of raw material, as it has already ceased in other forms of production. In the end capital and intelligence will discover new methods for the production of raw material, through which the monopoly of particular regions will be broken down. A careful study of the conditions of production and of the physical characteristics of other regions will show what obstacles confine the production of each kind of raw material to its present limits and how these obstacles may be displaced. A passive dependence upon the crude production of ignorant men in favored localities leads to high prices and monopolies. An active policy, on the other hand, by encouraging the use of capital and intelligence at home, will create new industries and open up new regions where civilized men can displace the natural production of the regions now furnishing the world with raw material.

The present condition of the production of raw materials creates a special need of activity on the part of the more civilized races so as to remove the remaining obstacles to economic progress. The rapid growth of population and of new wants has caused a great increase in the demand for all kinds of raw material, and this demand tends to increase more rapidly than the increase of the production in those regions from which we obtain our raw material. I refer especially to those 
crops which we obtain from semi-tropical countries. They are now produced under very crude conditions by the least progressive nations. As a result the production of sugar, coffee, spices, and other such crops is limited to a few favored localities where nature supplies all the conditions necessary to production. Only a few islands or specially favored localities upon the continents have that combination of climate and soil which is necessary for the easy production of these crops. These localities must also be naturally healthy to enable the people to avoid the disadvantages of the tropical climate. All these combinations are seldom found in one place, and as a result only a small part of the whole semi-tropical region is of any use to civilized man. The demand of the civilized world for these products has now increased to such an extent that the supply can no longer be obtained from the more favored localities. As a result of these circumstances we are paying monopoly prices for all this class of articles. By this I do not mean that there has been any marked increase in the price of these articles. I simply mean that we are paying twice or perhaps three times as much for them as we would pay if they were produced under civilized conditions.

There can be but one way of escaping from this difficulty. These articles which are produced at present under natural conditions must be cultivated by civilized people under artificial conditions. In other words, they must be cultivated in places where nature is less favorable and does less for the production of the crop, but where this disadvantage is counteracted by the 
greater efficiency of the labor in civilized countries together with a greater use of capital. This contest of natural and artificial production is clearly illustrated in the competition between the beet-sugar industry, to which I have referred, and that of cane-sugar. Germany has capital and skill, but they work under the disadvantage of an unfavorable climate. Cuba, however, has all these climatic conditions, but lacks skill and capital. German civilization cannot reduce the price of sugar to such a point as would be possible if the same skill and labor were employed in Cuba. It can, however, reduce the price of sugar far below what it would be if we depended solely upon the present Cuba for our sugar.

Perhaps the best illustration of all is in this country. There is no region of the world more poorly fitted for the cereals, and especially for wheat, than the great corn belt of Northern Illinois and the adjacent States. Yet the cultivation of wheat in this region has revolutionized its production. The disadvantage of the West in having a soil poorly adapted to wheat was more than balanced by the skill and intelligence of its people. All the great inventions reducing the cost of raising, cutting, binding, and threshing the wheat are the results of the contest between American skill and intelligence working under adverse natural conditions and the less intelligent farmers in lands more favored by nature. Natural and artificial production were pitted against one another, and the success of the artificial proves-what there would be no need of proving but for free-trade fallacies-that skill and intelligence 
are more powerful factors in national prosperity than nature or climate.

These examples, however, are mercly single illustrations of a thought which can be applied in many directions. The production of coffee is as much above its necessary cost as was the cost of sugar. Capital and skilled labor in less favored localities than Java or Brazil could produce our coffee at a lower price than we now pay for it. The same can be said of tobacco, or of rice, or of tea, or any other of those semi-tropical crops or fruits for which the demand of civilized people is growing so rapidly and must grow still more rapidly in the future with every increase in the variety of our wants.

The same difficulty presents itself in the production of other kinds of raw materials. Our natural forests will soon cease to give us that quantity of wood which we need. If the price is to be kept at any reasonable figure it must result from the artificial cultivation of trees in large sections of our country. With natural production alone we shall soon have a very high price for timber, increasing with each succeeding age.

Another illustration is that of wool. At the present time the greater part of our wool is raised in semicivilized nations, in distant places like Australia or parts of the far West which are not yet filled up. There is no way by which the ever-increasing densand for wool can be supplied from these natural sources without an increase of price. The area of Australia is limited, and what is more, the part of it devoted to wool will gradually decrease. The development of 
agriculture must in time reduce the quantity of land used solely for raising sheep. The people of Australia are as dissatisfied with their dependence upon the production of wool as the people of the North were with the production of wheat. They recognize how large a part of the productive capacities of their land is wasted while sheep-raising is the leading industry. The growth of national life and the spirit of independence will soon create among them a desire for a more active policy through which their industries will be diversified and their land put to better uses. The result is that the supply of wool from these sources is limited, and we must expect as time goes on to have a higher price for it until the more civilized races resort to raising sheep in connection with their agriculture.

In no respect is a passive reliance on free-trade a greater failure than in the production of wool. England admitted wool free of duty to get cheaper wool, yet at the end of thirty years its price had risen fifty per cent. Even at its present low price it is as costly as before the free-trade epoch. The regions of the world fitted only for sheep-raising are not sufficiently extensive to supply the wool needed for the world's consumption, and it is a delusion to hope for cheaper wool from such a source.

The same truth reveals itself in the production of iron as well as of coal. The mines of England from which in the past so large a part of the world's supply of iron has been produced are now becoming exhausted, or at least they have reached the limit of their productivity. We must expect a steady rise in the 
price of iron-ware unless new regions are developed in America which have the favorable conditions for the iron industry. The development of American ironworks is essential to keeping the price of iron in the present place or to any further reduction in it.

The progress of our civilization depends upon the cheapening of food and raw material; but a great mistake is made by assuming that free-trade and a passive policy can bring about this result. High prices alone do not cause producers to use better methods of production. Free commerce has separated these producers so widely from consumers that the high bid of the latter for food and raw material does not add to the inducement of the former to improve production. The producers now get little benefit from the high prices the consumers must pay. The monopolies between them absorb the difference between producers' and consumers' prices, and thus prevent those changes in the production of food and raw material which fair prices to producers would bring.

An active policy can secure what mere high prices cannot. It can create a demand for new crops, and thus enable the land to be used for what it is best fitted. Increase the variety of crops, and farmers can become more prosperous, even with present prices. Cause the land through free-trade to be used for one crop, and the highest prices will not compensate for the decreasing fertility of the soil. Farmers' interests lie in fair prices for many crops, and not in high prices for one crop. Their interests therefore harmonize with consumers' interests. The only policy that can bring 
prosperity to both classes is the one that will create a demand for all kinds of food and raw material under conditions that will allow civilized men to produce them. Shut out crude natural production, and we will get our food and raw material from our neighbors at a lower price than ever before.

There is, therefore, a duty devolving upon the more advanced nations of the world. Unless they take those measures necessary to bring under civilized conditions all those productions which are now carried on by partially-civilized races, we must expect the price of raw material to increase gradually and an everincreasing part of the whole produce of the world to pass into the hands of those who own the natural resources now in use. All these industries must be transferred to the civilized nations by the introduction of a more scientific production. We must take from landholders in these favored localities and from the states that oppress them all that revenue which comes to them from the present use of their land before the conditions will be favorable for a more scientific cultivation of the soil in semi-tropical regions. The best way to civilize these regions will be to displace their industries by those of the more civilized races. This policy will break up the present combination of landlords and state by which the people are kept down and enable them to develop into a higher civilization with that skill and capital which is needed to make them and the regions which they occupy more useful to the whole world. 


\section{CHAPTER XII.}

THE CONSUMPTION OF WEALTH.

IN the preceding chapters the attention has been directed to the material environment of the American people and the manner in which this environment may be made most useful. There is, however, another side to the economic development of the American people of equal importance. We must not only make the best use of all our material resources to get from our environment all possible assistance, but we must also in a large degree adjust ourselves to that environment so that our pleasures and wants can be easily supplied from the material resources by which we are surrounded. To a people like the American, who are almost unconscious of the immense possibilities of their country, an examination into the causes which at present prevent a more varied consumption of wealth is of supreme importance. It hardly needs proof that the consumption of wealth by the American people is not as well directed as it night be. That consumption of wealth is the most advantageous which creates a demand for the products of the soil in that proportion which will allow the best use of the soil. If while a field, when its powers are fully utilized, can yield two hundred bushels of wheat and five hundred bushels of corn there should be a demand for five hundred bushels 
of wheat and only two hundred of corn, it is plain that the land must be used too often for wheat and the soil will not be as productive as it might be with a change in the demand for wheat and corn. The total production of the field being reduced, the labor of the community needed to supply itself with food would be greatly increased.

It is also necessary to call attention to the fact that our present consumption is not final. What we eat and wear are to a large degree the results of past conditions when our ancestors lived in another environment in other lands. These acquired habits have created in us a liking for particular articles of food, and are accompanied by prejudices keeping us from using many articles which could now be produced with great advantage. We are at the present time rapidly undergoing radical changes in our diet. This fact can be clearly seen by an examination of any grocery-store. Twenty years ago the ordinary store contained only a few staple articles consumed by all the people. These, together with meat, potatoes, and bread, formed the sole diet. Every grocery-store now contains a great variety of articles not found in it during any previous period. A rapid increase in variety could not happen if there was not a growing demand on the part of the American people for a great number of new articles for their food-supply.

This change in diet is to a large extent due to a great decrease in the price of many articles not formerly consumed by the people in large quantities on account of their high price. Of these articles, sugar forms the 


\section{THE ECONOMIC BASIS OF PROTECIIION.}

best illustration. The changes of the last few years have reduced the price of sugar by at least fifty per cent. Sugar can now be produced as cheaply as flour. The result is everywhere apparent. A large part of our diet is sweetened, and many articles of food are thus made pleasant which formerly were distasteful. The rapid transit caused by the use of steam has greatly reduced the price of fruit all over our country and enables every one to make many kinds of fruit a prominent part of his diet. Cheap sugar is also an important element in the increased demand for fruit; because when sweetened it is much more easily preserved and more pleasant to eat.

The needed adjustment of the consumption of the. American people to their environment was delayed a long time on account of the commercial relations of our country. The first settlers must raise what they can export,-articles having a great value in a small bulk. So long as the leading crops of America were corn, tobacco, and wheat, but small progress could be made in the adjustment of Americans to American conditions. It was natural also that first settlers coming from other countries should desire articles suited to their late homes and have a prejudice against any other diet. The small use which the American people make of corn is a result of such prejudices. It is unfortunate that an article so well fitted for the American soil should be kept so completely out of use on account of the habits and customs which our forefathers acquired in other countries and where corn could not be raised. If the ancestors of the American people had come from 
a corn-producing country these prejudices could not have existed, and more rapid progress would have been made towards the adjustment of our consumption to the necessary conditions of our country.

The same effect of European conditions shows itself in our clothing as well as in our food. Our ancestors were reared in a country very productive of wool and in which there was no cotton. In modern times there has been a great change in the relative value of wool and cotton. Wool has become more expensive, while cotton goods have been, through the use of machinery, greatly reduced in price. Our mode of dressing was formed when wool was the cheaper article, or perhaps it is better to say the only article. Had our ancestors come from a country where cotton was in common use, our external garments would have been made of cotton and not of wool. As the result of habit and custom we adhere to the use of wool when we might be properly and warmly clothed at much less expense. I refer particularly to our external garments. The same warmth needed to withstand our rigid climate of winter might be obtained by using wool as undergarments. This grade of wool is still very cheap, and can easily be produced in America. We can get thus any amount of warmth without great cost, but the long wools from which our external clothing is made have become very costly. Such garments must in the end be displaced by some cheaper form of clothing, perhaps of cotton, unless the future gives us some article more in harmony with good taste. The change from woollen to cotton clothing has already taken place to some ex- 
tent. Women use calico and muslin extensively, and laboring men have also found that warmth and cheapness are best combined with woollen underclothing covered by a jacket and overalls made of cotton. The latter protects the former from wear and dirt, and can be replaced with but little expense when worn out. The accepted idea that cotton garments cannot be made warm is a false one. Cotton when first introduced was used as a substitute for linen. To make it resemble linen as closely as possible a hard finish was given it. The way cotton is spun and woven makes cotton garments cool. Cotton, however, resembles wool more closely than linen, and where the cloth made from it is given a soft finish, it feels like wool. The use of cotton in our winter garments is rapidly increasing, and the day is not far distant when many of them will be woollen more in name than in fact.

In the temperance movement and its effect upon the diet of the American people still another good illustration of the change going on at the present time in consumption can be seen. At an early period, when drinking habits where formed by our ancestors in Europe, the price of barley and rye from which drinks were largely made, was very low. The people had no better means of utilizing these cereals than in making their liquor. The great increase in the demand for food has increased the price of all those articles from which beer and whiskey are made. As a result a liquor diet, while being the cheapest diet our ancestors could procurc, has become, relative to the cost of other articles of food, a costly diet. Even if there were no 
temperance movement, the effect of this change in the price of the articles composing a liquor diet would be to diminish their use. The change in cost of the diet of drinking men as compared with the diet of temperance men is the real cause of the growth of the temperance movement. The temperance people have now a great economic advantage over those who drink, and this advantage must gradually increase with every change in the consumption of the American people through which a greater use is made of cheap food.

Perhaps what I mean by the effect of our economic environment upon the consumption of the American people can be best illustrated by the changes which are now taking place in various kinds of live-stock. Hogs, sheep, and cattle as well as men are importations from Europe, but these animals do not have the customs and prejudice of men to overcome before they can be adjusted to their new conditions. There has been a rapid development of new breeds, especially of horses, hogs, and cattle, through which animals are obtained more fitted for American conditions. Especially is this true of the hog. The Western hog is a different animal from that found elsewhere. He has become adjusted to his new conditions with corn as his food. The same effects are visible in cattle, but not to so great a degree. The difficulty in sheep-raising lies in the fact that sheep have not yet become adjusted to American conditions. We need an American breed of sheep, which can stand our climate and eat the products best fitted for American soil.

Even in the color of our clothing there must be great 
changes made before our adjustment to American conditions is complete. The conditions of soil and climate determine the color best fitted for use. This can be plainly seen in the various colors used by railroad companies in painting their cars and buildings. Each section of the country requires a different color to enable the car to best withstand the changes in heat and climate to which it is subjected. Notice also the changes which have been made in painting our houses and barns. Formerly white was regarded as the only proper color for a dwelling. White, however, is the color least suited to the dry, dusty climate of America, and economy, as well as taste, has forced the American people to make use of other colors more adapted to our climatic conditions. Even in our clothing there must be a gradual diminution in the amount of white which we wear. The use of white clothing was well suited to the moist climate of Europe from which our ancestors came and to which they were adjusted. Our preference for white is a result of these conditions. Gradually, however, there has been a displacement of white by other colors more suited to American conditions, and in the end all our white garments are likely to be displaced by those more harmonious to our economic surroundings.

The best use of all our land can only follow more varied consumption on the part of the American people. There are now immense tracts of land which cannot be utilized because the American people do not demand the crops for which they are fitted. So long as the home market does not demand any other articles 
for food than those staple ones to which our ancestors in Europe were adjusted, there can be but little use made of those parts of our country for which wheat and grazing are not well fitted. At present our population is aggregated in those regions best fitted to the production of the cereals, and in these regions only those sections are well cultivated for which these crops are suited. If our consumption is greatly modified so as to include a much greater variety of crops suited to American soil, centres of population will be created in new regions of which little use is made at present, and in the regions now occupied the introduction of a more suitable rotation of crops will add greatly to their productivity.

It is of special importance to point out how our food-supply may be greatly increased without any addition to its cost, so as to show how our increasing population may be supplied with food without bringing about such an unequal distribution of wealth that will stop all progress. It is unfortunate that the American people, accepting without thought a European point of view, should rely solely upon the increase of machinery for their progress and not upon changes in the consumption of wealth. In reality much greater improvement in the condition of the American people could be made by adjusting our consumption to American conditions than by all the machines that it is possible to devise. It certainly was a great improvement when the development of our railroad system allowed the use of the Western lands for wheat, but changes in consumption can do more for improving the condition 
of the American people than it was possible to obtain through our railroads. The productivity of our soil when used for crops other than wheat will be increased many fold, and thus increase the average return for labor, even though there is a rapid increase in population. The region of our country now used for the production of tobacco is also well fitted for various kinds of fruit. Suppose the American people should change its demand from tobacco to fruit so as to allow the use of this region for fruit instead of tobacco, what a great increase there would be in the productive power of the nation! Beyond a doubt ten times the present populaiion could be supported by these regions if the land were used for fruit and similar crops instead of tobacco.

Suppose further there should be a change in the demand of the people from whiskey to sugar. The same fields from which corn is obtained to make the whiskey is well suited for sorghum from which sugar is made. It is easy to see how great would be the increase of productive power if the American people ceased to demand whiskey and in its place put a diet making a free use of sugar.

If all these considerations are properly viewed they show how great must be the changes in consumption before the American people are really adjusted to American conditions. By trying to remain European and holding on as long as we can to old habits and customs, we reduce the productivity of the American soil and make the return for labor much lower than it might be. This tenacious holding on to the old also has a marked tendency to bring the American nation 
prematurely into a static state, in which the people would be so bound down by habit and custom that they cannot overcome the obstacles which stand in the way of the best use of the soil. While these tendencies remain dominant a large part of our capital and labor is wasted by opening up land for use which we will not want when we become better adjusted to our environment. Much of the poorer land of the Eastern States never would have been opened up if our consumption of food was in harmony with American conditions. The light soil of our hills is often better fitted for the cereals than are the fertile valleys in the same regions. As a result the poorer soils are those now mostly used, and the large quantities of capital and labor which were needed to bring them into use will be a total loss as soon as other crops better fitted for the valleys are demanded by the people.

American civilization has before it a series of problems to solve before all food products can become cheap. The crude natural production of which we now make so much use must be displaced by scientific production in one region after another. With the increased demand for any article produced in a crude fashion the price rises until the inducements are so great that scientific production overcomes the obstacles in its way and displaces crude natural production. A passive policy on the part of the people cannot prevent high prices of crudely-produced articles: It merely retards the change to scientific production and lengthens the period of high prices. It would be a great saving in the end if an active policy on the part of our gov- 


\section{THE ECONOMIC BASIS OF PROTECTION.}

ernment should raise the price of our agricultural products now crudely produced so as to give more inducement to scientific production. It is not likely that the American people will change their demand for food from those articles produced in a crude fashion to other articles better fitted for the soil and requiring scientific production until the present price of these articles has been greatly increased, either through the action of the government or through the effect of an increased demand on the part of a growing population. This period of high prices must in the end come, and it is for the American people to decide whether they will passively allow an unequal distribution of wealth to force the change in consumption through which they must go, or whether they will by a wise policy hasten this period and remove those obstacles which stand in the way of the change.

Every increase in the price of the staple articles of consumption hastens modifications in consumption. Even taxes upon these articles would assist in our development. These taxes would fall upon the less progressive part of the community, which does not change its consumption. The more progressive part makes use of new articles better suited to American conditions, and thus not only avoids the taxes, but really increases the productivity of its labor. Taxes on tobacco and liquors are of particular value in this respect, and have done much towards reducing the use not only of these articles, but also the whole diet consumed by those who use them.

We are now in a position to contrast more fully than 
before the different conceptions presupposed by dynamic and static states of society. The latter state supposes a steady diminution of the average return for labor through the gradual utilization of poorer opportunities for labor. In the dynamic society the temporary high prices of single articles are followed by such changes in consumption and production that will lead to a cheaper production by more scientific methods. Each wave of high prices breaks down some old barriers to changes in production and consumption through which the better adjustment to the economic conditions of the country is possible. In the static state prices rise slowly, never again to fall permanently. In the dynamic state prices rise more quickly, but changes in production and consumption follow through which prices are again reduced to a lower point than ever before. Through a long period, then, the tendencies of these two social states are exactly opposite. In the static state there is a steady increase in the price of all those articles which are likely to become natural monopolies, while in the dynamic state these articles, through changes in consumption and production, are steadily reduced in price, although there must be periods during which their prices are high in order to force changes in production and consumption.*

\footnotetext{
* For a more complete discussion of the principles of consump tion, see my "Consumption of Wealth."
} 


\section{CHAPTER XIII.}

THE CRITERION OF EFFICIENT PRODUCTION.

IT is the aim of national policies and the desire of the people to make labor as efficient as possible. Some criterion of efficient production is needed, therefore, by which the relative advantage of different modes of production can be tested. The usual standard is that of results measured in price. It has been claimed by Mill, as well as by others of his mode of thinking, that the power of underselling is an unfailing test of the efficiency of production, and that it implies a better economy of skill and indicates a greater produce for the same labor. This test, however, is not a good one except in a static state of society. If the efficiency of each laborer and the modes of production are fixed quantities, then the adjustment of society in such a way that cheapness ensues will perhaps lead to the best results. As soon, however, as we take into consideration a society in a dynamic state the need of some other test becomes plain. In such a society we cannot accept the present efficiency of the various classes of laborers as a permanent quantity, nor can we regard in the same way the productivity of land and other natural resources. All of these elements which go to make up the total production are constantly changing, and we must keep in mind not merely the present state of pro126 
duction and how to make laborers of to-day efficient, but also the best way to increase the productive power of labor and productive capacities of land and other natural resources.

Cheapness is a test of the results of production, while the need of a dynamic state is a test of the power to produce. We must, however, contrast productive power and efficiency so as to find an adequate test for each. Efficiency is to be measured by the results in particular industries, productive power by the average result in all industries. An increase of productive power implies a development of the industrial qualities of the nation or the utilization of the greater part of them. The society uses more skill, intelligence, forethought, capital, and other like indications of a higher intelligence, but this higher intelligence applied to the various industries does not give a like increased return in all of them. A given increase in productive power may result in a very large increase in efficiency in one industry and a very small increase in another. We must judge the productive power, therefore, by the average increase in the industry of the whole nation, and not as we judge efficiency by the increase in particular industries. Productive power cannot be tested by the results in particular industries, because in any given industry the results from an increase in productive power may not be manifest. Productive power is a consequence of the general intelligence of society and is to be judged by the civilization of the people. Civilization causes intelligence, and intelligence gives productive power. If this reasoning is correct, then the 
skill and intelligence of the people-in other words, their civilization-is a much better test of the efficiency of their production than is the cheapness of the commodities they produce.

An increase of productive power does not show itself in prices unless it adds more to the efficiency of labor in one industry than in another. Prices will not fall if wages rise as rapidly as the increase of productive power permits. If all commodities are produced with fifteen per cent. less labor, prices would not be altered. If, however, with the same average, one part requires twenty per cent., and the other ten per cent., less labor, the former falls in value ten per cent. Cheapness, - therefore, merely shows the differences in the increase of productive power, not its full increase.

With a higher civilization some of the articles produced will have a higher price, but productive power as a whole is so much increased that a greater quantity of products can be secured by the people even if the price is ligher. Some articles will have a higher price because an increase in productive power of a nation does not increase the efficiency of the labor to a like degree in all industries. With every increase of productive power there is a change of the relative efficiency of different industries. At one stage in a nation's development the efficiency of labor in particular industries increases very rapidly, while it remains stationary in other departments. In one stage of its development the efficiency of labor in the production of cotton goods may double, while in iron or silk there may be little change. At a second increase of 
productive power during another period the efficiency of labor in producing iron may rapidly increase, while silk and cotton will change but little. Now comes a third period in which perhaps the increase of productive power will show its effect in the production of silk, and the efficiency of the laborers producing silk will increase rapidly, while that of workmen employed in other occupations, even though having a greater productive power as a whole, will not be materially changed.

To illustrate, let us suppose that a society is going through a series of industrial transitions, and that in changing from the one industrial stage to another the increase in productive power is fifteen per cent. We will further suppose that in changing from the first to the second stage judged by the efficiency, the labor producing article $\mathbf{A}$ increases in efficiency five per cent., in the article $\mathrm{B}$ ten per cent., $\mathrm{C}$ fifteen per cent., D twenty per cent., E twenty-five per cent., - thus making the average increase fifteen per cent. In the second stage, therefore, the articles $A$ and $B$ will have a higher price than before, $\mathrm{C}$ will have the same price, while $\mathrm{D}$ and $\mathrm{E}$ will have a lower price. Notice that this increase in productive power would place the nation at a disadvantage in producing the articles $A$ and $B$, while it would increase their advantage in producing $D$ and E. Suppose now another like increase in productive power through which the efficiency of the labor producing $A$ is increased forty per cent. above what it was in the first stage of industrial progress, B twenty per cent., $\mathrm{C}$ thirty per cent., $\mathrm{D}$ twenty-five per cent., $\mathrm{E}$ thirty per cent., - thus making a second average increase 
of fifteen per cent. The article $\mathrm{A}$ would now have a lower price than in the first industrial stage, $\mathrm{C}$ and $\mathrm{E}$ the same price, while $\mathrm{B}$ and $\mathrm{D}$ would be dearer than at first. In the second stage the nation was at a disadvantage in producing $A$ and $B$, while in the third stage the nation is at a disadvantage in producing $B$ and D, arising from the fact that the increased productive power when applied to these articles does not give as great results as in the production of other commodities. During the second stage the nation would have an advantage of producing $\mathrm{D}$ and $\mathrm{E}$, while in the third stage the advantage would be greatest in producing $A$. In other words, the change from the second to the third stage would change the direction of the labor of the nation from $\mathbf{D}$ and $\mathrm{E}$ to $\mathbf{A}$. Although in each higher stage some articles are dearer than before, yet as the productive power has been increased there has been as a whole a gain by the people, and more products can be obtained by the average citizen.

Perhaps my thought can be more clearly seen from the following table:

\begin{tabular}{|c|c|c|c|c|c|c|}
\hline \multirow{2}{*}{$\begin{array}{l}\text { Per Cent. of } \\
\text { Average In- } \\
\text { crease. }\end{array}$} & I. & II. & III. & IV. & v. & VI. \\
\hline & & 15 & 30 & 45 & 60 & 75 \\
\hline A. . & 100 & $105-$ & 140 & 145 & $150-$ & 175 \\
\hline B. & 100 & 110 & $120-$ & 160 & 170 & 180 \\
\hline 6 & 100 & 115 & 130 & $135-$ & 165 & 170 \\
\hline D. & 100 & 120 & $125-$ & $140-$ & 160 & 185 \\
\hline 7 & 100 & 125 & 130 & 145 & 155 & $165-$ \\
\hline
\end{tabular}


In this table the numerals refer to the successive stages-in industrial progress, in each of which the productive power has increased fifteen per cent. The letters refer to different articles produced by the labor of the nation. In the first stage the productive power of the nation in each article is placed at one hundred per cent. as a basis, and the increase in productive power in various subsequent stages can be seen from the table by observing what increase in the power of producing this commodity takes place in each of the stages. Notice how the efficiency of labor as applied to the production of different commodities varies with each industrial stage. These changes must continually take place as long as there is an increase in the productive power, because each increase of productive power has unlike results in different occupations. To show more clearly in what commodities the labor in each stage is at a disadvantage, I have placed a minus sign after those articles in each column where the labor is relatively least productive. In this way it can be seen that during the five stages each article is twice produced at a disadvantage; thus showing very clearly the enormous force exerted in a dynamic state to change labor from one occupation to another.

Suppose, further, we take two societies, one of which remains static in the first stage while the second is dynamic and advances through the several stages I have indicated. At each stage some articles would be cheaper in the static society than in the dynamic one, and as a result there would be a tendency to cease producing these articles in the dynamic society. At every 
stage in the industrial development, however, the new articles become the cheap articles, and others which were cheap become the dear articles. If exchanges should take place between the two societies the labor of the dynamic society would now be forced into new occupations, and the labor and capital expended in developing the industries whose products are now relatively dear will be a loss to that society. There would then be a continual loss in capital and skill of producers through ceasing to produce certain articles, and another serious loss through removing the obstacles needed to produce the new commodities for which their labor is now efficient; yet at the next industrial stage these articles which they have ceased to produce will perhaps be those for which their labor will be most productive; since the increase in productive power may add much more to the efficiency of the production of these articles than to that of other articles. In this case the expense of reintroducing these industries must be borne a second time, and there would also be an additional loss resulting from taking labor and capital from the industries of the preceding stage into those of the next stage.

If we accept cheapness as a criterion of efficiency, in the second stage A drops out to reappear in the third, in the second stage $\mathrm{D}$ drops out to reappear in the fourth, while in the fourth stage $\mathrm{C}$ drops out to reappear again in the fifth.

From these facts it will be seen that for a nation passing through a scries of dynamic stages, different considerations must form the part of a good national 
policy than if a nation remained static in any one stage. The people must estimate not merely the present efficiency of their labor, but also the losses and gains which will come to them in passing from one industrial stage to another. They must keep in mind also that an industry which is at a disadvantage in one stage of progress will often be the place where their labor is most efficient in subsequent stages.

There is also an additional reason why a dynamic nation should keep alive those industries where its labors are at a disadvantage. The more mechanical industries for which a low class of labor is better fitted are likely to go to the lower civilization; yet the more mechanical an industry is the more likely is it that inventions will be discovered by which it will change to an industry fitted for the higher civilization. As capital and skill are constantly displacing crude labor, the cruder the form of production the more likely is it that in the next stage of the industrial development of the nation this industry will, through inventions and improvements, be changed into one requiring a large quantity of capital and much skill on the part of the laborers. Thus the industries into which the higher civilization can with advantage put its labor in the next industrial stage are likely to be those in which the lower civilizations now put their labor. On this account there is a great difficulty in changing the industries as a nation advances, because the industries into which its labor should go are now the industries of distant lands. Through this advance sugar must change from Cuba to Germany, nails from England to 
Pittsburg, cotton goods from India to England, linen goods from Holland to Ireland, silk from China to France, and ships from Maine to the river Clyde.

If the labor of a nation is devoted to a few occupations there is a bar to its development into a higher industrial stage, because its labor must be changed into occupations so different from those in which the laborers are now placed. This is to be seen in the present condition of the South. It is now changing from one industrial stage to another, and as a result its labor will have to be transferred from the present leading occupations to new ones. Sugar, tea, and silk, wool and iron, are to be the industries of the South at no distant period; yet all these industries are now located in distant lands and cannot be easily domesticated. It is even difficult to convince Americans that the rapidlyincreasing intelligence of the South makes new occupations desirable. So firmly have free-trade notions become rooted in their modes of thinking, that they are led to suppose that the actual industries of the nation are those in which its labor is most productive. Very likely the production of cotton was the most efficient industry of the South during the period of slavery, but the new conditions of the South, the rapid increase in the intelligence of its people and the increase of its capital are bringing about an industrial revolution which will change the relative advantage of its leading industries.

The cost of an advancing civilization shows itself in the price of single articles. If it requires more skill to produce $B$ than $A$, the industrial qualities needed to produce $B$ when applied to $A$ will cheapen it. If pro- 
ducing $\mathrm{C}$ requires still more skill, its production will in a like manner cheapen $A$ and $B$. The new industries of a progressive nation thus seem to be a burden, because a higher price is needed to develop the superior skill required to make commodities in a new way, yet when this skill is also applied to the old industries the gain in them far exceeds the loss from the temporary ligh prices in the new industries.

If a nation in a dynamic state keeps its industrial development harmonious, labor and capital can easily pass into new industries where the increase of productive power makes it most efficient. In this way its advance becomes regular and certain, and it moves much more rapidly along the course of its industrial development than would be possible if it accepted cheapness as a criterion of industrial efficiency and allowed its labor to become concentrated in a few industries, ont of which it could not be taken without great trouble and expense. The prominent injury of free-trade arises from its tendency to force the labor of each nation into a few industries. The productive power of a nation cannot increase very rapidly while its labor is employed in so narrow a scope. In any industry but few industrial qualities are called into activity, and the productive power of a nation which relies solely on a few industries is relatively small. The nation can sell cheaply, but its laborers have so little productive power that they cannot buy much even of what is cheap. Free-trade may reduce the price of some commodities, but it reduces productive power so much more rapidly that the people suffer from it. 


\section{CHAPTER XIV.}

SHALL THE IDEAL OF AMERICAN CIVILIZATION BF NATIONAL OR COSMOPOLITAN?

From the earliest times until within the eighteenth century the development of the world moved along national lines. Each nation was to a large degree isolated from the others, and whatever development took place within it was passed over to other nations very slowly if at all. In this way each nationality had concrete ideas and a spirit of opposition to the other nations which retarded to a large degree the progress of the world. During the eighteenth century, however, there grew up another type of thinking. The ties of nationality ceased to have their original force, and many persons thought to set aside entirely all those marks and characteristics which showed them to be natives of particular localities, and would have themselves regarded as citizens of the world rather than of their own nation. They would choose the best characteristics from each nationality, and in this way hoped to blend into a new whole a type of man which would incorporate within itself all the higher characteristics of each race. This change in tone had a great influence upon the civilization of the eighteenth century and brought with it many advantages. It helped to make the nations known to one another and to incorporate in 
each nationality some of the good features of other nations.

Soon, however, this feeling settled down into a species of dogmatism. Its advocates upheld definite dogmas which they regarded better than any other. They were without any historical sense, and thought their own ideas were not merely better for themselves but also better for all times, conditions, and societies, and that the views they held and their mode of living and acting should be impressed upon all other races and localities, no matter what their stage of development. Types of men not fitted for this statical state would be ground out of existence by competition, and thus the whole civilized world blended into one united whole with definite ideas, doctrines, and modes of living.

This species of cosmopolitanism grew out of the dogmatism of the last century before the educated classes were influenced by the later developments of economic, sociological, and biological knowledge. During this century there has been a reaction against this cosmopolitan feeling, and in almost every nation there has arisen a new type of thinkers who strive to have their civilization become more closely adjusted to the peculiar conditions of its own environment. This is not a wish to restore the old type of civilization. They see the errors in the old national feeling as clearly as do their opponents. It is not provincialism that they wish, but real nationalism. Provincialism includes a hostility to other nationalities and the desire to cling to that which has grown up within its narrow bounds. It is 
also a static conception, and would hold each locality to those ideas and modes of living which they have acquired from past times. Nationalism, on the contrary, is a dynamic movement, and seeks to bring each nation through a series of changes and developments that would bring a better harmony between its social conditions and its economic environment. It assumes that each nationality through differences of climate, soil, and other natural conditions has an economic environment peculiar to itself to which a particular type of man is best adjusted, and that a series of nations of different types, each fitted to its own environment, will make a better use of the world and reach a higher civilization as a whole than any one type could if it endeavored to occupy the whole world and retain the common characteristics. This type in reality would be adjusted to the conditions of some one locality only, and in other regions its adjustment would be so meagre that the civilization would necessarily take a low form and make a poor use of the natural resources around it. On the contrary, adjust the people of each nation to its own environment and mankind will be better adjusted to natural conditions of the whole world than in any other way.

Nationalism tends to adjust the people of a nation more closely to their environment and thus develop all its natural resources. Its inhabitants learn to enjoy those pleasures which the environment can best offer and to live on those kinds of food which can be procured most cheaply. It is a dynamic movement bringing organic changes into the nation with each development of its 
environment. The nation is kept organically together in its development, but at the same time the influence of the environment is so prominent that any change in it makes a corresponding change in the organic whole of the nation. Cosmopolitanism, however, overlooks the need of this adjustment to objective conditions and tends to adjust man more closely to a particular social condition and to cut off those portions of society lacking the dominant traits. It stops differentiation and presses the nation into a fixed social state. It blends into a chemical whole the body of thought and characteristics peculiar to the nationality. It throws around the nation strong bonds from which it is hard to break and thus results in a statical state.

A national ideal is not opposed to the general good of the whole world. If each nation makes the best use of its own land and of its own resources the whole world will be utilized to the fullest degree. Each nation is also more useful to its neighbors if its resources are put to the best use than if its land and resources were used in a way subordinating its nationality to that of some other nation. The land of India, for example, being better fitted for rice than for wheat, the utility of India to the whole world is much greater if its resources are developed by its own people and its land used in a way most useful to them, than if the whole country were turned into a wheat-field for the benefit of distant lands. As a wheat-field, India would doubtless be of considerable use to other nations, but its utility to them and the commerce that it would have with them would be much greater if its land is used to 
support its own people than if it were used merely to raise wheat. As long as the land of one nation is used directly to support the people of another nation only the lowest forms of commerce and the crudest material will be a part of the trade with other nations. This form of commerce ceases when the land of a nation is used to support its own people, but as new forms of commerce develop and in articles of greater value and utility, the total commerce is much greater than it otherwise would be. Commerce increases with national prosperity, and whatever gives prosperity to each individual nation increases the prosperity of the whole world. The value of American trade to Europe has increased just in proportion as the American people have used their land to support themselves. American trade is now much more valuable to Europe than if it were a series of Irelands furnishing them with food.

There are particular reasons why America should make a national movement its ideal rather than try to blend its civilization into a common form with that of Europe. Our opportunities for development. and progress are much more favorable than those of Europe, and we can develop into a higher civilization much more rapidly than it is possible for them to do. Share with them, and our progress must be as slow as theirs; isolate ourselves from them, and our new soil and great natural resources, coupled with the activity of our people, will push us rapidly into a higher social state, where many of our present economic difficulties will disappear. When we have reached this national 
ideal and adjusted ourselves to our environment our civilization will be easily propagated in other lands, and thus our national progress in the end means the progress of the whole world. Just as the successful development of American political ideas quickly swept all before them throughout Europe, so a higher economic system once put into successful operation in America would have little difficulty in finding imitators all over the world. All the parts of such a system must develop together so as to enlarge our productive power sufficiently to supply our more urgent wants. It will not be possible for us to create a higher civilization and rely solely upon the development of a few industrial qualities as a basis of this civilization. A new civilization means the development of new industrial qualities harmoniously united with those we now have. It also means new tastes and habits through which a new order of consumption is formed and a better adjustment to our food-supply made possible. When we reach this new equilibrium in harmony with American conditions, then and only then can we expect to exert a commanding influence upon the development of the other nations, and force them to break away from their present economic conditions and adjust themselves to a higher social state. If we show the world how a people can become educated, how skilled labor can be placed and maintained in all industries, how the consumption of the people can be modified so as to make the best use of its land, and how all forms of internal improvements can be successfully inaugurated and carried out, other nations 
will be compelled to follow in our footsteps and displace that mass of cheap laborers which now retards the development of every nation. Just as English isolation from the Continent developed new industrial sonditions so superior to those of the Continent that in the end other nations were forced to adopt them, so a national policy in America can develop a still higher industrial state, and thus compel other nations to make use of the same means in their development.

Do not forget, however, that this development must be an organic whole and that a new equilibrium must be obtained before our influence can be fully exerted. There is not enough difference between three-eighths and seven-sixteenths of a solution of our economic difficulties to make it for the advantage of the whole world that we slould immediately divide up the results of every industrial advance with other nations. Better let them accumulate in America until we solve problems of a higher civilization, and then the propagation of results will be much easier. Our success will thus become the success of the whole world. In this respect the example of England should be followed. She did not give up her isolation until her industrial superiority over that of Continental nations had been established in every leading industrial line. So great has been her supremacy that as yet no other nation has been able to displace her, even though they have diligently sought to domesticate English methods of production. If we add to the skill of our laborers, make a greater use of capital and join with this in an organic whole all that a higher education can give, we can then reap 
as great an advantage from commerce as England is now doing.

To accomplish these results an active policy should not be confined to a tariff. We must broaden the lines of our national activity if we would secure the best results with the least effort. Internal improvements are of special importance, and the industrial development of the South needs particular encouragement. The key to national prosperity lies in Southern prosperity. The South is the natural market of the West, and until its resources have been developed so that it becomes the market for Western produce, the West itself cannot have that prosperity which its superior natural conditions should give it. Educational activity is also of prime importance. A broader education is needed to show Americans how to adjust themselves to American conditions. There is a special need of manual training by which the efficiency of each individual laborer will be increased more rapidly. So far in the development of American industry we have relied almost wholly upon machines, capital, and shrewd managers to obtain our industrial success. The development resulting from these causes has been remarkable; yet a still more remarkable development might be obtained if each individual laborer should have his efficiency increased as fully as a manual education would allow. Money spent by the nation in increasing the skill and intelligence of the people is the most efficient means of leading to an adjustment to the new conditions of the country. Whatever obstacles to eccnomic progress the nation must overcome to reach a 


\section{THE ECONOMIC BASIS OF PROTECTION.}

higher civilization can, with the aid of an education, be overcome with less protection, and the period of protection will also be shortened.

It is, however, unwise to set a definite limit to the period of national development throngh which a protective policy is advantageous. With a higher ideal of the future of America the initial period preparing for its realization is extended. The greater and grander our civilization is to become, the longer must be the dynamin movement which will bring us into it. The error of free-traders lies in their low ideal. They judge we have almost reached the limit of our progress, and hence our economy should conform to a static ideal. The mistake they are making is similar to that of Columbus. He was right in thinking that by sailing westward he could reach Asia. He was wrong in his estimation of the distance and the obstacles in the way. On the economic chart of Adam Smith his Asia almost touched the shores of Europe. In a few days' sailing Le hoped our civilization would reach its goal and ideal. While the discovery of vast seas and unknown Americas makes our Asia more distant than ever, it has to a corresponding degree increased the possibilities of our development. We live in a larger and better world than our fathers supposed, yet we must work barder and longer if we are to become a nation which can master its difficulties and secure its rewards.

\section{THE END.}




\section{THE PREMISES \\ $O B$ \\ POLITICAL ECONOMY.}

By SIMON N. PATTEN, Ph.D. (Halle),

PRORESSOR OF POLTTICAL, ECONOMY IN THE UNIVERSITY OR PENNSYLVANIA,

12mo. Cloth. Price, \$1.50.

\section{TESTIMONIALS.}

From the Boston Beacon.

"Clergymen, students of society, men and women of the world, whoever has a heart and any interest in the dismal science of wealth, should not fail to read Patten's 'Premises of Political Economy." "

\section{From the Chicago Inter-Ocean.}

"A modest, but powerful treatise. In its line, it is one of the marked books of the season, and to the student of the deep and vital questions of economics it must be highly valuable."

\section{From the New YoRK INDEPENDENT.}

"The best thing in the book is an important objection to the law of groundrents as started by Ricardo. . . . By following this analysis out completely, we see how Carey and Ricardo each seized upon a half-truth; the two being apparently, but not really, inconsistent with one another. 'This is admirable, and shows our author at his best. His theory of the 'limited return' from land is almost as good."

\section{From the NEw YoRK Critrc.}

"While free-trade forms directly the subject of only one chapter out of eight, the argument of the whole book is directed against that let-alone policy which has reigned supreme in the English school of political economy, and of which free-trade is only the most conspicuous application. . . . Whatever we may think of the doctrine of laissez faire, of the policy of protection, the originality and ability of the work before us cannot be questioned. It contains almost the only cogent and weighty arguments against the docttines of Ricardo and Malthus that we have seen."

For sale by all Booksellers, or will be sent by the Publishers, post-paid, on receipt of the price.

\section{J. B. LIPPINCOTT COMPANY, \\ PUBLISHERS,} 7x5 ANd 727 Market Strket, Philadelphia. 
PUBLISHED BY AMERICAN ECONOMIC ASSOCIATION.

\section{The Stability of Prices.}

VOL. III. No. 6. Paper, 73 Conts.

"In the present monograph he (Prof. Patten) greatly improves his account of rent, and applies it to an explanation of great and frequent changes in the prices of commodities." -PrOF. F. H. Giddings, in Political Science Quarterly.

\section{Malthus and Ricardo.}

\section{Vol. IV. No. 5. Paper, 78 Cents.}

"On the other side of the ocean, where the same dispute between the deductive and the historical methods is going on, one of the most talented of the younger investigators, Prof. Simon N. Patten, who has learned to know the empirical methods at its very source in Germany, breaks a lance for the neces. sity of deductive reasoning, claiming for it equal validity with the inductive method."-Pror. BöHM-BAwERK.

PUBLISHED BY THE UNIVERSITY OF PENNSYLVANIA.

Political Economy and Public Law Series.

\section{The Consumption of Wealth.}

No. 4. Paper, Bo Cents.

" Dr. Patten gives here a magnificent piece of work on the theory of consumption. His distinction between the 'natural order,' in which we desire goods for consumption, and the 'economic order' is of as far-reaching Importance as it is ingenious."-Cenrad's Yahrbilcher, 1889.

\section{The Principles of Rational}

\section{Taxation.}

No. 6. Paper, Bo Cents.

"In this treatise Prof. Patten recognizes the inadequacy of our present system of levying taxes to meet the increasing demands of city and local governments for improvements, and seeks to find, through an analysis of our industrial condition, some new point of view through which a solution of the perplexing problem of taxation may be solved."-Record and Gwide, January $25,1890$. 


\section{SIR WALTER SCOTT'S}

\section{WAVERLEY NOVELS.}

\section{NEW LIBRARY EDITION.}

Complete in 25 Octavo volumes. Cloth, $\$ 1.75$ per volume; half morocco, gilt top, $\$ 2.25$ per volume. In sets: Cloth, gilt top, $\$ 43.75$; half morocco, $\$ 56.25$; half calf, gilt, marbled edges, $\$ 80.00$; three-quarters calf, $\$ 100.00$.

Special Edition, with 135 Extra Steel Plates (in all 185 Plates). Sets: In cloth boards, 25 volumes, $\$ 62.50$; threequarters calf, extra, $\$ 125.00$.

"We are glad to say of it that it is the most desirable set that we have ever seen. It is tastefully bound in a coat of dark blue and elegantly lettered in gold, with gilt top. The type is large and beautiful, and is set in a margin at least an inch in width of clear white paper. Each volume contains a fine full-page steel-engraving, either a portrait or copy of some famous picture illustrating the story, and a steel vignette. The edition needs but to be seen to be coveted by every lover of beautiful books." Boston Advertiser.

\section{PEOPLE'S EDITION.}

Complete in 6 volumes. Illustrated. 12mo. Extra cloth, per set, $\$ 9.00$. The same in 12 volumes. Extra cloth, per set, $\$ 12.00$; half calf, $\$ 24.00$.

\section{CENTENNARY EDITION.}

Complete in 25 volumes. I 2mo. Cloth, $\$ 31.25$; half calf, $\$ 62.50$; three-quarters calf, extra, gilt top, $\$ 75.00$.

\section{EDINBURGH EDITION.}

Complete in 48 volumes. 16 mo. Cloth, $\$ 60.00$; cloth, gilt top, $\$ 70.00$; half calf, gilt, $\$ 120.00$.

For sale by all Booksellers. Sent by the Publishers, post-paid, on receipt of the price. J. B. Lippincott Company, 715 and 717 Market Street, Philadelphia. 


\section{Thackeray's COMPLETE WoRKS.}

These are all Author's Editions, printed in England, from the original plates. The illustrations are all from electros from the original blocks. All the editions contain the author's latest revisions, and the typography, illustrations, paper, and binding are in every way THE BRST. For sale by all Booksellers. Askfor the Original English Editions.

\section{STANDARD EDITION.}

Printed from new type, on fine paper, and including some of $\mathrm{Mr}$. Thackeray's writings which have never before been collected. With the exception of the Edition de Luxe it is the largest and handsomest edition that has been published. With illustrations by the author and others. 26 volumes. 8 vo.

Vanity Fair. . . . . . z vols. Irish Sketch Book . . . . I vol.

Pendennis . . . . . . . z vols. Barky Lyndon ....... I vol.

ThB Newcomes ..... 2 vols. Roundabout Papres .... x vol.

Harry Esmond ...... x vol. Four Georgrs ........ I vol.

The Virginians ...... 2 vols. Lovel, the Widower. . . I vol.

Philip . . . . . . . . z vols. Miscrllangous Essays ... . vol.

Hogarty Diamond .... vol. Contributions hrom Punch i vol.

Book of Snors ...... I vol. Burlesqurs . . . . . . I vol.

Christmas Books ..... x vol. Catherine .........

Paris Sketch Book .... I vol, Ballads .......... I vol.

Yellowplush Papers ... I vol.

Price per volume : English cloth, uncut edges, $\$ 3 . \infty$; cloth, gilt top, $\$ 3.00$. In sets: English cloth, $\$ 78.00$; cloth top, $\$ 78.00$; three-quarters calf, $\$ 150.00$; full tree calf, \$200.00.

\section{LIBRARY EDITION.}

With illustrations by the author, Richard Doyle, and Fredericic Walker. Complete in 24 volumes. 8vo. Price per volume: English cloth, gilt, $\$ 2.00$. In sets: Extra cloth, $\$ 48.00$; half calf, $\$ 84.00$; three-quarters calf, extra finish, gilt top, other edges uncut, \$93.00; tree calf, $\$ 120.00$.

\section{POPULAR EDITION.}

Complete in 26 volumes. $12 \mathrm{mo}$. Profusely Illustrated. Price per volume : Extra cloth, \$1.25. In sets: Extra cloth, \$32.50; half calf, $\$ 65.00$; three-quarters calf, extra finish, gilt top, other edges uncut, $\$ 78.00$.

\section{GLOBE EDITION.}

Complete in 13 volumes. Crown 8 vo. With over 70 illustrations. Price per volume : Extra cloth, $\$ 1.25$. In sets : Cloth, $\$ 16.25$; half calf, $\$ 32.50$; three-quarters calf, extra finish, gilt top, other edges uncut, \$0.00.

\section{HANDY EDITION.}

Printed in clear type, on fine paper, from a new set of plates (pocket slze). Complete in 27 volumes. Price per volume: Half cloth, 50 cents; half morocco, $\$ 1.00$. In sets: Half cloth, uncut edges, $\$ 13.50$; half morocco, gilt top, $\$ 27.0$.

For sale by all Booksellers. Sent by the Publishers, post-paid, on receipt of the price. J. B. Lippincott Company, 715 and 717 Market Street, Philadelphia. 


\section{Charles Dickens's Works}

\section{THE ILLUSTRATED STANDARD EDITION.}

Complete in 30 volumes. 8vo. \$2.50 each.

This edition is printed on a finer paper and in larger type than has been employed in any previous edition. The type has been cast especially for it, and the page is of a size to admit of the introduction of all the original illustrations.

Sketches By "Boz."

David Copperfield.

PICKWICK PAPERS.

Oliver TWist.

Bleak House.

Nicholas NickLeby.

LitTle Dorrit

Old Curiosity Shopand Reprinted The Uncommercial. Traveller.

Pieces.

Great Expectations.

Barnaby Rudge and Hard Times. Our Mutual Friend.

Martin Chuzzlewit.

American Notes and Pictures History of England

FROM ITALY.

DOMbey and Son.

Christmas Stories.

EdWin DroOd aNd OTher Stories

Cloth, $\$ 60.00^{* *}$; half calf, gilt, marbled edges, $\$ 120.00^{*}$; three-quarters calf, extra finisb, gilt top, other edges uncut, \$125.00*; full tree calf, gilt, \$1 75.00 .

\section{LIBRARY EDITION.}

12mo. With the original illustrations. 30 volumes. Each work sold separately in the original red cloth binding. Per volume, $\$ 1.50^{*}$. In sets: Cloth, 30 volumes, $\$ 45.00^{*}$; three-quarters calf, $\$ 90.00$.

\section{TAVISTOCK EDITION.}

Large 12 mo. 30 volumes. Cloth, $\$ 45.00$; half calf, gilt top or marbled edges, $\$ 90.00$; three-quarters calf or morocco, $\$ 100.00$.

\section{HANDY EDITION.}

32 volumes. $16 \mathrm{mo}$. Half cloth, 50 cents per volume; Half morocco, \$1. .0 per volume.

The clear type, fine thin paper, with uncut edges and neat binding, make these little books as elegant as one need wish, while the low price will enable all lovers of Dickens to possess, at a very small outlay, a good edition of his works.

For sale by all Booksellers. Sent by the Publishers, post-paid, on receipt of the price. J. B. Lippincott Company, 715 and 717 Market Street, Philadelphia. 


\section{BULWER'S NOVELS.}

THE WORKS OF SIR EDWARD BULWER-LYTTON, BART.

\section{LIBRARY EDITION.}

Complete in 47 volumes. Large type. Fine tinted paper. 12mo. Extra cloth, per set, $\$ 58.75$; half calf, gilt top, $\$ 117.50$.

\section{THE LORD LYTTON EDITION.}

Complete in 25 volumes. Large $12 \mathrm{mo}$. With Frontispiece. Extra cloth, black and gilt, per set, $\$ 31.25$; sheep, $\$ 43.25$; half calf, gilt top or marbled edges, $\$ 50.00$; half morocco, new style, gilt top, $\$ 62.50$.

Each novel sold separately, in extra cloth, per volume, \$1.25.

The Caxtons ........ I vol. Pglham ......... I vol. My Nover. . . . . . . 2 vols. THz Disowned....... I vol. What will He do with It? 2 vols. Paul Clifford....... I vol. Devergux ........ I vol. Ernest Maltravgrs .... I vol. The Last Days of Pompeil $x$ vol. Godolphin .......... I vol. leila Calderon, and PilAlice ........... I vol. grims.......... I vol. Night and Morning.... I vol. Rignzi ........... I vol. Lucretia ......... I vol. The Last of reg Barons. . I vol. A Strange Story ..... I vol. Harold ......... I vol. Kenglm Chillingly .... I vol. Eugres Aram ....... I vol. The Parisians ....... I vol. Zanoni ......... I vol. Pausanias ....... I vol.

"We know of no series so desirable in every respect as this."-Philadelphia Evening Bulletin.

"It makes one of the most attractive and valuable series to be found in any library for reading in distinction from reference. It is at once handsome and cheap."-Chicago Evening Journal.

For sale by all Booksellers. Sent by the Publishers, post-paid, on receipt of the price. J. B. Lippincott Company, 715 and 717 Market Street, Philadelphia. 


\section{OF THE \\ Works of William H. PrescotT}

With Notes by John Foster Kirk.

\section{STUDENT'S EDITION.}

In five vols. THE CONQUEST OF MEXICO.

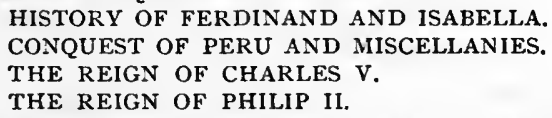

Cloth binding, \$1.00 per vol. Price per set, cloth, \$5.00; extra cloth, gilt top, \$6.25; half calf, gilt top, \$12.50.

\section{NEW POPULAR EDITION.}

Cloth binding, gilt top, historical style.

The Conguzst of Mexico, 3 vols., cloth......\$1.50

Conquest of Peru, 2 vols., " ...... 2.00

Ferdinand and Isaeella, 3 vols., “ $\ldots \ldots \ldots$

The Reign of Charles V., 3 vols., “ $\ldots \ldots \ldots$

The Reign of Philip II., 3 vols., " . . . . . 3.75

Miscellanies,

Life of Prescott, I vol., " ....... 1.25

Complete set, 16 vols., cloth, gilt top, $\$ 16.50$; without Life, 15 vols., $\$ 15.25$; 16 vols., half calf, $\$ 32,00$.

\section{LIBRARY EDITION.}

12 vols. Cloth, \$2.50 per vol. Price per set, cloth, \$30.00; half calf, marbled edges, $\$ 48.0$.

\section{EXTRA ILLUSTRATED LIBRARY EDITIONS.}

History of тнв Conquest of Mexico. With a Life of the Conqueror, Fernando Cortez, and a View of the Ancient Mexican Civilization. By W. H. Prescotr. 2 vols. 8vo. Containing all the steel plates on India paper and maps that have appeared in former editions. With Thirty Phototype Illustrations. Large type, on fine paper, and neatly bound in half morocco, gilt top, \$10.00 net.

History of the Reign of Ferdinand and Isabella the Catholic. By W. H. Prescotr. 2 vols. 8 vo. Containing all the steel plates on India paper and maps that have appeared in former editions. With Thirty Phototype Illustrations. Large type, printed on fine paper, and neatly bound in half morocco, gilt top, $\$ 10.00$ net.

For sale by all Booksellers. Sent by the Publishers, post-paid, on receipt of the price. J. B. Lippincott Company, 715 and 7I7 Market Street, Philadelphia. 


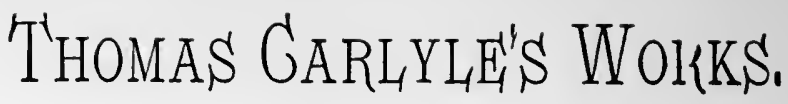

\section{THE ASHBURTON EDITION.}

This Edition is handsomely printed, and contains the Portraits and Inluse trations. 17 volumes. Demy 8vo. Cloth, gilt top, $\$ 2.00$ per volume: three-quarters calf, $\$ 4.50$ per volume.

Vol. I. The French Revolution.

Vol. II. The French Revolution and Past and Present.

Vol. III. Sartor Resartus; Heroes and Hero Worship.

Vol. IV. Life of John Sterling, Life of Schiller.

Vol. V. Latter-Day Pamphlets, Early Kings of Norway, Essay on the Portrait of John Knox.

Vols. VI., VII., VIII. Letters and Speeches of Oliver Cromwell. Vols. I., II., III.

Vols. IX., X., XI., XII., XIII., XIV. History of Frederick the Great. Vols. I., U., III., IV., V., VI.

Vols. XV., XVI., XVII. Critical and Miscellaneous Essays. Vols. I. II., III.

\section{PEOPLE'S EDITION.}

In 38 volumes. Square $16 \mathrm{mo}$. Bound in cloth. Per vol., 50 cente. 38 volumes. Cloth, \$ro.oo. Or in ro volumes. Cloth, \$1750: half calf, gilt, \$40.00. tree calf, \$00.00.

\section{LIFE AND WORKS OF CHARLOTTE BRONTÉ.}

LIBRARY EDITION.

With Life. Illustrated. 7 volumes. Crown 8vo. Per set: cloth, \$ro.50: half calf, gilt, \$24.50; three-quarters calf extra, gilt top, \$25.00. Each volume sold separately in cloth, $\$ 1.50$.

Jane Eyre, Shirley, Villette, The Professor, Wuthering Heights, The Tenant of Wildfeld Hall; and The Life of Charlotte Bronté, by Mrs. Gaskell.

JANE EYRE. People's Edition, \$r.00."

\section{HANDY EDITION.}

Each volume containing a Frontispiece. 7 volumes. Per volume: Cloth, so cents: half morocco, \$1.00: half calf, per set, $\$ 54.00$.

For sale by all Booksellers. Sent by the Publishers, post-paid, on receipt of the price. J. B. Lippincott Company, 715 and 717 Market Street, Philadelphia. 


\section{HALF-HOUR SERIES.}

\section{HALF-HOURS WITH HUMOROUS AUTHORS.}

Just issued. Selected and arranged by CHARLES MORRIS. In four volumes. 12mo. Cloth, gilt top, $\$ 6.00$; half morocco, $\$ 10.00$; three-quarters calf, $\$ 13.00 ;$ Russia, in case, $\$ 20.00$.

This work, 1niform with the following, embraces some of the choicest writings of the best American, English, and foreign humorists, and completes the Half-Hour Series commenced a few years ago.

\section{HALF-HOURS WITH THE BEST AMERICAN AUTHORS.}

Selected and arranged by ChARLes MORRIs. Complete in four crown 8vo volumes. Cloth, $\$ 6.00$; half morocco, $\$ 10.00$; three-quarters calf, $\$ 13.00$; Russia, in case, $\$ 20.00$.

"It is a book over which every American book-lover must rejoice. Gems have been gathered from every department of literature, and have been edited with a taste and refinement fitting their own high character." Chautauquan.

\section{HALF-HOURS WITH AMERICAN HISTORY.}

Selected and arranged by CHARLES MORRIS. Two volumes. Crown 8vo. Uniform with "Half-Hours with the Best American Authors." Cloth, $\$ 3.00$; half morocco, $\$ 5.00$; three-quarters calf, $\$ 6.50$.

"The history becomes almost a romance, so absorbingly interesting is it throughout." -St. Louis Republic.

\section{HALF-HOURS WITH THE BEST FOREIGN AUTHORS.}

Translations selected and arranged by CHARLES MORRIS. Four volumes. Crown 8vo. Uniform with " Half-Hours with the Best American Authors." Cloth, gilt top, $\$ 6.00$; half morocco, $\$ 10.00$; three-quarters calf, $\$ 13.00$; Russia, in case, $\$ 20.00$.

"The collection is in truth an extremely interesting one, and the books of the time offer no better method for a ready acquaintance with the "choice and master spirits' of literature in other speech than our own."New York Times.

For sale by all Booksellers. Sent by the Publishers, post-paid, on receipt of the price. J. B. Lippincott Company, 7I5 and 7I7 Market Street, Philadelphia. 


\section{AlliBOnE'S QuOTATIONS.}

By S. Austin Allibone, LL.D. Complete in three volumes. Price per set: In cloth, $\$ 9.00$; half Russia, \$12.00. The set contains the following works :

\section{POETICAL QUOTATIONS.}

Covering the entire field of British and American Poetry, from Chaucer to Tennyson. With Copious Indices. Both Authors and Subjects alphabetically arranged.

"It will at once rank, as his 'Dictionary of Authors' has long done, as the first and best book of the kind in the English language."-Harper's Magazine.

\section{PROSE QUOTATIONS.}

From Socrates to Macaulay. With Indexes. Authors, 544; Subjects, 571; Quotations, 8810.

"No well-supplied library can do without this work, and its convenlence to writers and thinkers makes it most welcome to readers." -New York Evening Express.

\section{GREAT AUTHORS OF ALL AGES.}

Being Selections from the Prose Works of Eminent Writers from the time of Pericles to the Present Day.

“The diversity, style, and classical finish of most of the matter, next to the food for the mind, moulds almost imperceptibly the channeis of thought of the reader, and creates a love for the higher realms of literature." - Pittsburgh Evening Telegraph.

\section{A CRITICAL DICTIONARY of ENGLISH} Literature and British and American Authors,

Living and Deceased, from the Earliest Accounts to the Latter Half of the Nineteenth Century, containing over Forty-six Thousand Articles (Authors), with Forty Indexes of Subjects. By S. Austin Allibone, LL D. Complete in Three Volumes. Imperial $8 \mathrm{vo}$. 3140 pages.

Extra cloth. \$22.50; sheep, marbled edges, \$25.50; half calf, gilt, $\$ 33.00$; half morocco, Roxborough, gilt top, 831.50 ; half Russia, $\$ 33.00$.

* For sale by all Booksellers, or will be sent by the Publishers, free of expense, on receipt of the price.

\section{J. B. LIPPINCOTT COMPANY,}

7×5-787 MARKET STREET,

-. - PHIlladelphia, PA. - . - 


\section{FOREIGN CLASSICS FOR ENGLISH READERS.}

Edited by Mrs. Oliphant. I6mo. Extra cloth. Price, $\$ 1.00$ per volume.

The purpose of this series is to present in a convenient and attractive form a synopsis of the lives and works of the great writers of Europe-who they were and what they wrote.
I. Dante
2. Voltaire
3. Paschal
4. Petrarch
5. Goethe
6. Moliere

VOLUMES NOW READY.
7. Montaigne
8. Rabelais
9. Schiller
ro. Calderon
II. Cervantes
12. St. Simon
13. Corneille and Racine
14. Madame de Sévigne
15. La Fontaine, etc.
16. Tasso
17. Rousseau

OTHER VOLUMES IN PREPARATION.

"No reader of taste can find these anything but delightful works, and welk worthy his attention."-Boston Evening Traveller.

\section{ANCIENT \\ CLASSICS \\ FOR ENGLISH READERS.}

A Popular Translation of the Classics. Edited by Rev. W. Lucas Collins. $56 \mathrm{mo}$. Fine cloth. Price, per volume, 50 cents.

Also the 28 volumes bound in 14 volumes, cloth extra, \$12.50: half calf, \$25.00.

2. Homer's Iliad

2. Homer's Odyssey 12. Euripides

3. Herodotus

4. Cazarar

5. Virgil

6. Horace

7. Aschylus

8. Xenophon

9. Cicero

ro. Sophocies

" Each successive issue only adds to our appreciation of the learning and skill with which this admirable enterprise of bringing the best classics within easy reach of English readers is conducted."-New York Independent.

For sale by all Booksellers. Sent by the Publishers, post-paid, on receipt of the price. J. B. Lippincott Company, 715 and 717 Market Street, Philadelphia. 


\section{READER's ReFEREnCe LibraRy.}

Io vols. 12mo. Half morocco, gilt top, in box. Per set, \$26.0.

"A most valuable addition to the library of the student, and to the clergy It ought to be specially useful."-New York Herald.

RACH VOLUME SOZD SEPARATELY, AS FOLZOWS:

BREWER'S HISTORIC NOTE-BOOK.

A Dictionary of Historic Terms and Phrases. \$3.50.

THE WRITER'S HAND-BOOK.

A General Guide to the Art of Composition and Style. \$2.50.

BREWER'S READER'S HAND-BOOK

Of Facts, Characters, Plots, and References. 3.50 .

BREWER'S DICTIONARY OF PHRASE AND FABLE.

Giving the Derivation, Source, and Origin of about 20,000 Common Phrases, Jllusions, and Words that have a Tale to Tell. New edition (Seventeenth). Revised and corrected. \$2.50.

BREWER'S DICTIONARY OF MIRACLES.

Imitative, Realistic, and Dogmatic. With Illustrations. \$2.50.

EDWARDS'S WORDS, FACTS, AND PHRASES.

A Dictionary of Curious, Quaint, and Out-of-the-Way Matters. \$2.50.

WORCESTER'S COMPREHENSIVE DICTIONARY.

Revised, enlarged, and profusely illustrated. \$2.50.

ROGET'S THESAURUS.

A Treasury of Fnglish Words. Classified and arranged so as to facili. tate the expression of ideas and assist in literary composition. \$2.50.

ANCIENT AND MODERN FAMILIAR QUOTATIONS.

From the Greek, Latin, and Modern Languages. \$2.50.

SOULE'S ENGLISH SYNONYMES.

A Dictionary of Synonymes and Synonymous or Parallel Expres. sions. \$2.50.

For sale by all Booksellers. Sent by the Publishers, post-paid, on receipt of the price. J. B. Lippincott Company, 7I5 and 7I 7 Market Street, Philadelphia. 
$$
\text { . }
$$

$=$

.

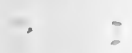

$=$ 



$$
=
$$

- . =
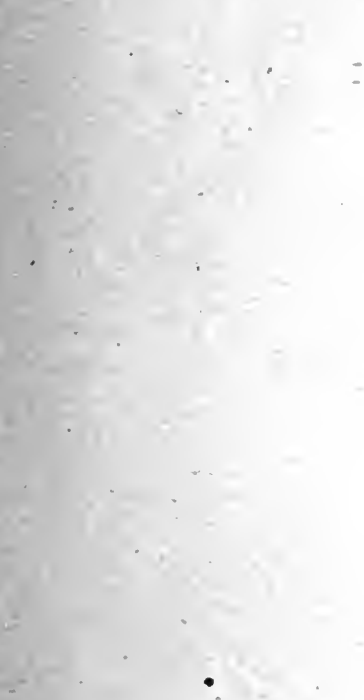


\section{University of Toron Library}

DO NOT

REMOVE

THE

CARD

FROM

THIS

POCKET

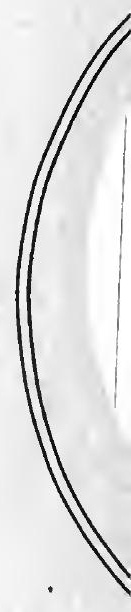

Acme Library Card Pocket Unuer Pat. "Ref. Inder Vwo". Made by LIBRARY BUREAU 
